The University of Southern Mississippi

The Aquila Digital Community

Master's Theses

Summer 8-2017

\title{
The Influence of Perceived Job Flexibility and Spousal Support On the Marital Satisfaction of Parents of Children With Special Needs
}

Katie M. Perlowski

University of Southern Mississippi

Follow this and additional works at: https://aquila.usm.edu/masters_theses

Part of the Social and Behavioral Sciences Commons

\section{Recommended Citation}

Perlowski, Katie M., "The Influence of Perceived Job Flexibility and Spousal Support On the Marital Satisfaction of Parents of Children With Special Needs" (2017). Master's Theses. 305.

https://aquila.usm.edu/masters_theses/305

This Masters Thesis is brought to you for free and open access by The Aquila Digital Community. It has been accepted for inclusion in Master's Theses by an authorized administrator of The Aquila Digital Community. For more information, please contact Joshua.Cromwell@usm.edu. 
THE INFLUENCE OF PERCEIVED JOB FLEXIBILITY AND SPOUSAL SUPPORT ON THE MARITAL SATISFACTION OF PARENTS

\title{
OF CHILDREN WITH SPECIAL NEEDS
}

\author{
by
}

Katie M. Perlowski

\begin{abstract}
A Thesis
Submitted to the Graduate School, the College of Education and Psychology, and the Department of Child and Family Studies at The University of Southern Mississippi in Partial Fulfillment of the Requirements for the Degree of Master of Science
\end{abstract}


THE INFLUENCE OF PERCEIVED JOB FLEXIBILITY AND SPOUSAL SUPPORT ON THE MARITAL SATISFACTION OF PARENTS

OF CHILDREN WITH SPECIAL NEEDS

by Katie M. Perlowski

August 2017

Approved by:

Dr. Lindsay E. Wright, Committee Chair

Assistant Professor, Child and Family Studies

Dr. Amanda L. Williams, Committee Member

Assistant Professor, Child and Family Studies

Dr. Heath A. Grames, Committee Member

Associate Professor, Child and Family Studies

Dr. Pat L. Sims

Chair, Department of Child and Family Studies

Dr. Karen S. Coats

Dean of the Graduate School 


\section{COPYRIGHT BY}

Katie M. Perlowski

2017

Published by the Graduate School

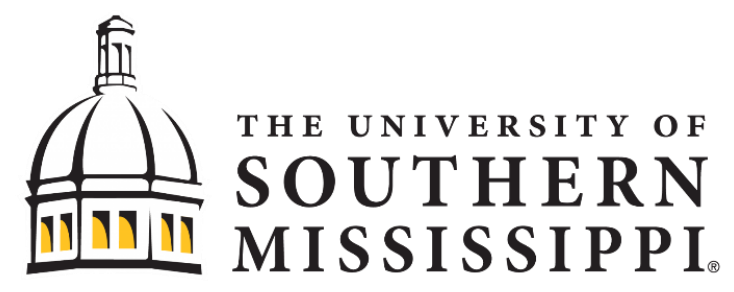




\begin{abstract}
THE INFLUENCE OF PERCEIVED JOB FLEXIBILITY AND SPOUSAL SUPPORT ON THE MARITAL SATISFACTION OF PARENTS OF CHILDREN WITH SPECIAL NEEDS

by Katie M. Perlowski
\end{abstract}

August 2017

Parents of children with special needs can experience more stress in their marriage than parents of children without special needs. Previous work has focused on the child as a major influence for the marital relationship, however this research sought to examine less commonly discussed factors that influence marital satisfaction for these parents. Perceived job flexibility and perceived spousal support in parenting were targeted as potential influencers. A mediation model was attempted to explain the mediating role of perceived spousal support in parenting in the relationship between perceived job flexibility and marital satisfaction. Results showed no correlation between perceived job flexibility and marital satisfaction. Positive correlations between perceived job flexibility and perceived spousal support in parenting were found and positive correlations were also seen between perceived spousal support in parenting and marital satisfaction. Analysis produced a more linear model of influence than the predicted mediation model. Implications of these findings were discussed. 


\section{ACKNOWLEDGMENTS}

First and foremost, I would like to thank my committee chair, Dr. Lindsay Wright, for her invaluable guidance, her personal interest in my research, and her support through this process. I would also like to thank another committee member, Dr. Amanda Williams, who readily responded to my many emails and who was instrumental in fostering my understanding of data analysis. Also, I would like to thank another committee member, Dr. Heath Grames, for his helpful feedback and his knowledgeable contributions during this process. 


\section{DEDICATION}

I would like to dedicate this project to the many families that I have had the honor to work with over the years and who are the inspiration for my research. I would also like to thank my family for all of the encouragement and confidence they have given me in

this pursuit. Additionally, I would like to thank my partner, Jeremy Chojnacki, as it is his support and his unfaltering belief in me that has helped me to achieve my goals. 


\section{TABLE OF CONTENTS}

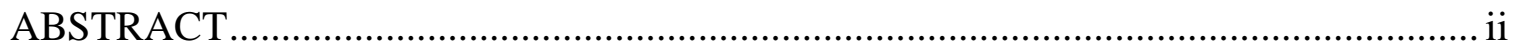

ACKNOWLEDGMENTS .............................................................................. ii

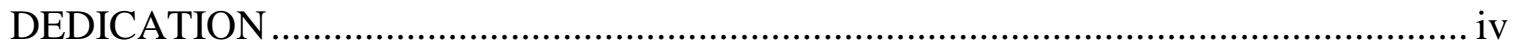

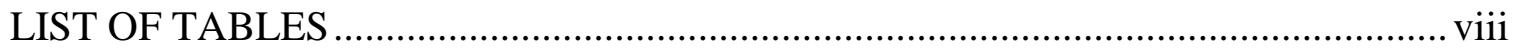

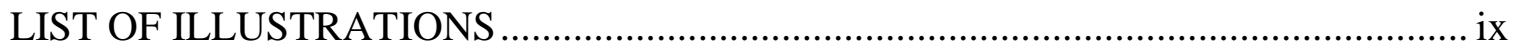

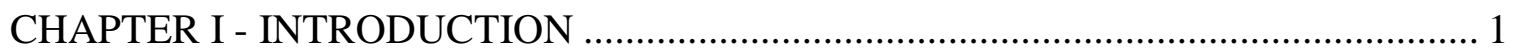

Definitions of Key Terms ................................................................................. 5

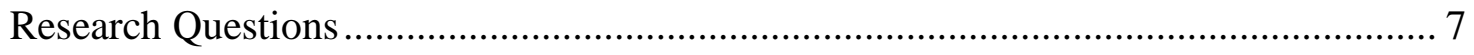

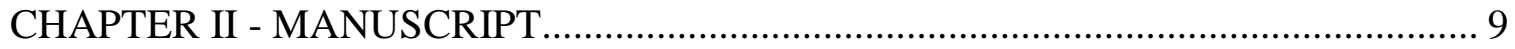

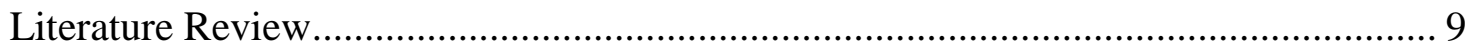

Bioecological Systems Model......................................................................... 10

Connecting Existing Literature to Bioecological Systems Model .......................... 11

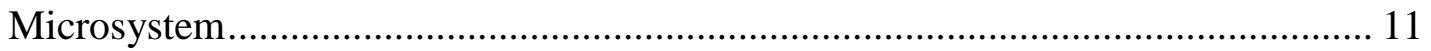

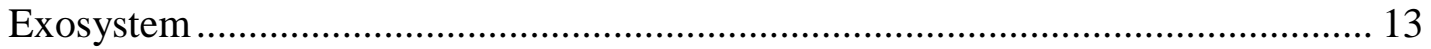

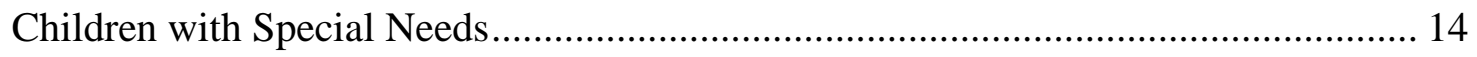

Perceived Spousal Support in Parenting .......................................................... 15

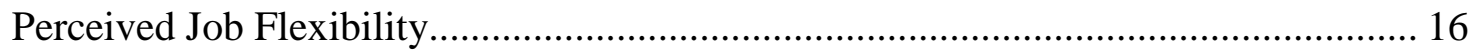

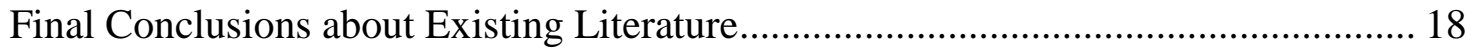

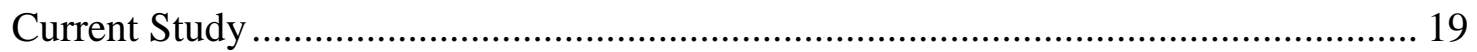




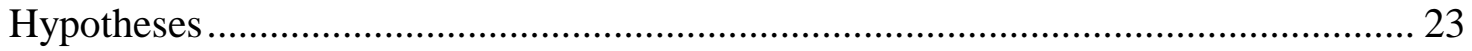

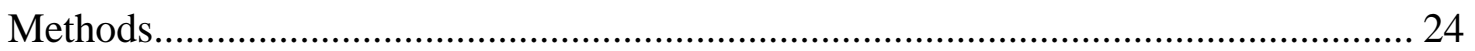

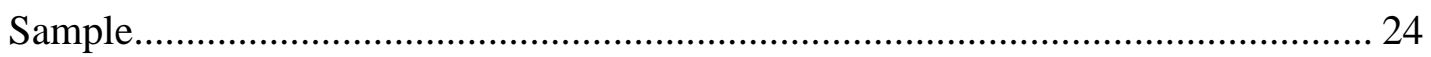

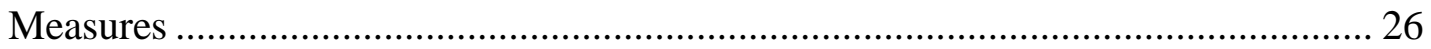

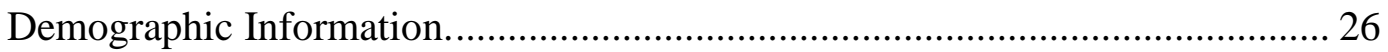

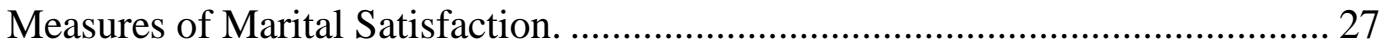

Measures of Perceived Spousal Support in Parenting. ...................................... 28

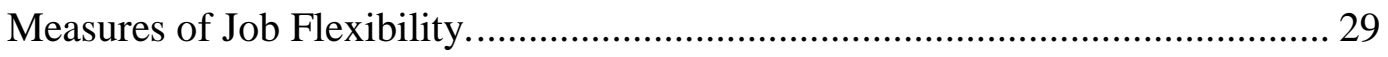

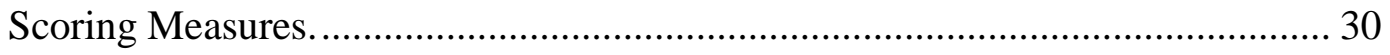

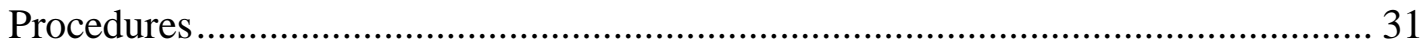

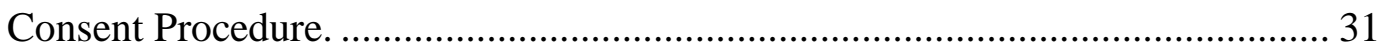

Survey Procedure. ................................................................................. 32

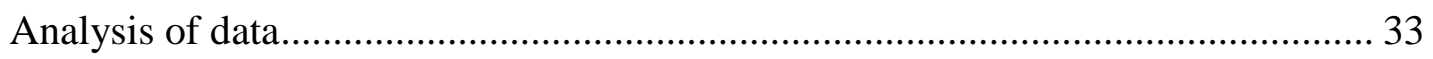

Descriptive Statistical Analysis. ................................................................. 33

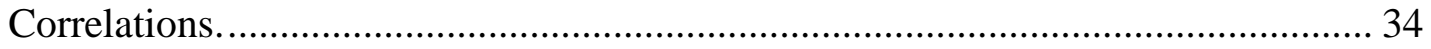

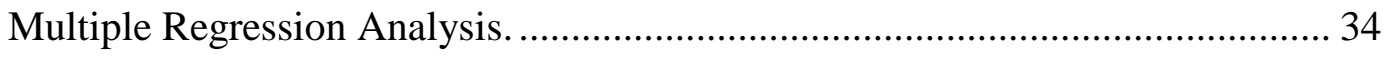

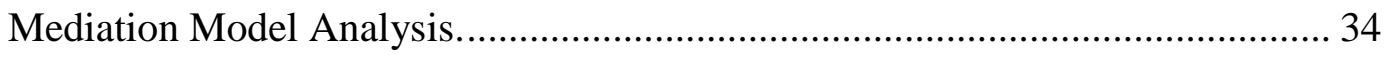

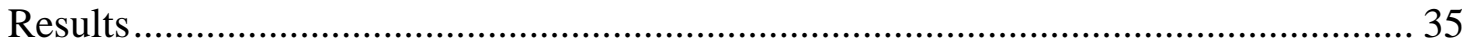

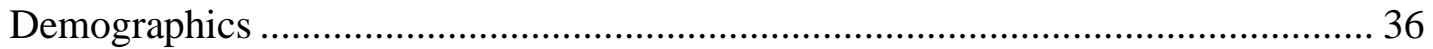


Marital Satisfaction

Perceived Spousal Support in Parenting .............................................................. 39

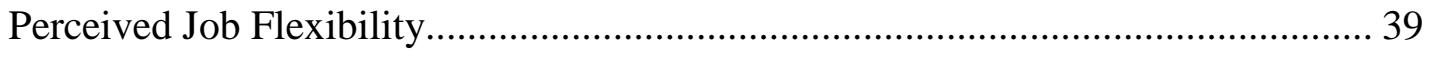

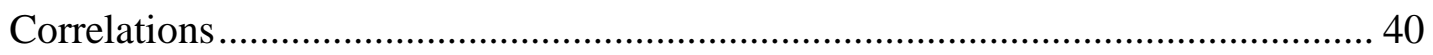

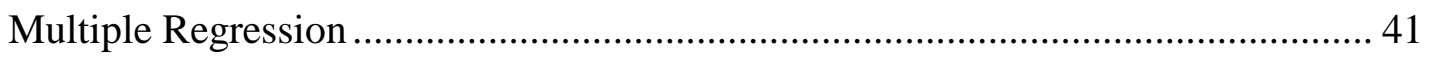

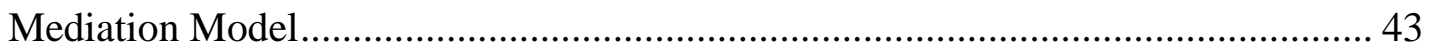

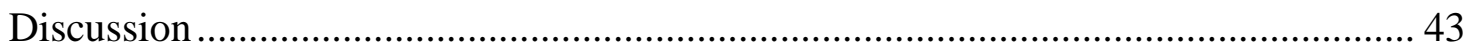

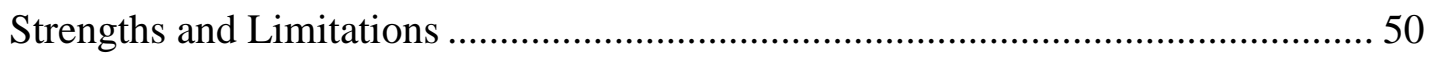

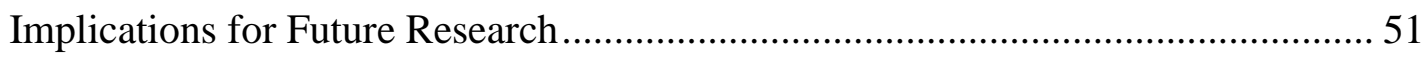

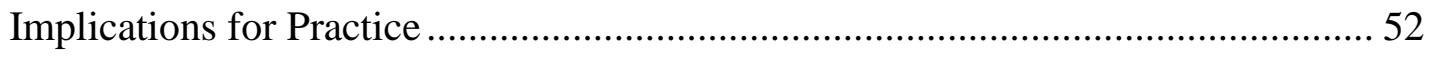

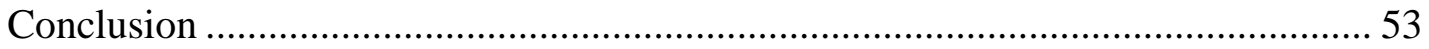

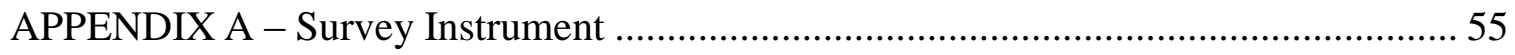

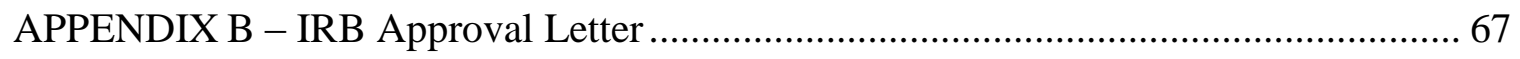

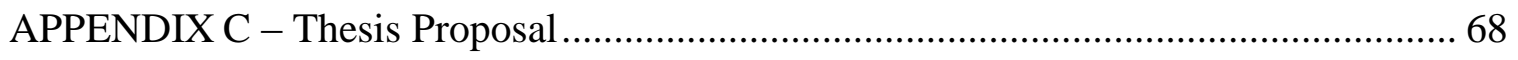

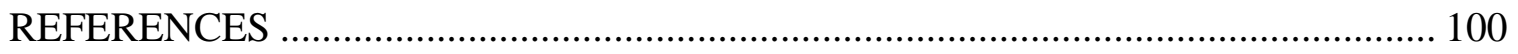




\section{LIST OF TABLES}

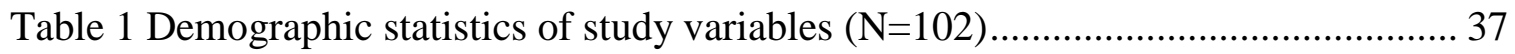

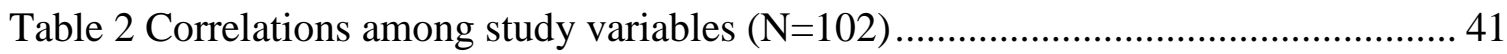

Table 3 Regression analysis results for study variables......................................... 42 


\section{LIST OF ILLUSTRATIONS}

Figure 1. Hypothesized mediation model of the relationship between job flexibility, perceived spousal support in parenting, and marital satisfaction.

Figure 2. Interpreted model of the relationship between job flexibility, perceived spousal support in parenting, and marital satisfaction based on the data analysis.

Figure A1. Hypothesized mediation model of the relationship between job flexibility, perceived spousal support in parenting, and marital satisfaction. 


\section{CHAPTER I - INTRODUCTION}

The marital satisfaction of parents who have children with special needs has been examined as a subject of interest by many family researchers (Daire, Munyon, Carlson, Kimemia, \& Mitcham, 2011; Kersh, Hedvat, Hauser-Cram, \& Warfield, 2006; Smith \& Grzywacz, 2014). As children with special needs tend to require more unique care than children without special needs, different dynamics may be observed among their families. Past research has focused on the interaction between the couple as it relates to their child's behavior (Kersh et al., 2006). While this is valuable to study, as children with behavioral issues do influence the rest of the family's functioning (Smith \& Grzywacz, 2014; Starr, 1981), there are other aspects that should be examined as well. With prevalence rates indicating that about $13 \%$ of children ages three to 17 years have a special needs diagnosis (National Center for Educational Statistics, 2016), there is a significant population of families who may benefit from research into marital satisfaction as it pertains to the parents of children with special needs.

Estimates suggest that nearly half of all marriages will end in divorce (Kazdin, 2000). While statistics on the occurrence of divorce within families of children with special needs may vary between sources (Barkley, Fischer, Edelbrock, \& Smallish, 1991; Minde et al., 2003; Wymbs et al., 2008), it has been estimated that as many as $70 \%$ to $80 \%$ of marriages of parents of children with special needs will end in divorce (Sobsey, 2004). The detrimental effects that divorce can have on a child are well-documented in recent years (Fergusson et al., 2014; Weaver \& Schofield, 2015; Woody, 2009), as the access to and the acceptance of divorce have become more prominent. Divorce can impact the social, mental, and physical well-being of children regardless of whether or 
not they have a special needs diagnosis, however, for children with special needs, these effects may be experienced in more nuanced ways (Fergusson, McLeod, \& John Horwood, 2014; Weaver \& Schofield, 2015; Wymbs et al., 2008). For children whose daily functioning relies heavily on set schedules and routines, this change in family structure could disrupt many aspects of their developmental progress because while parents in today's society tend to overschedule their children in an attempt to cultivate additional skills (Hofferth \& Sandberg, 2001), many children with special needs require strict scheduling in order to promote their functional abilities and ensure that all of their medical needs are met (Weaver \& Schofield, 2015; Wymbs et al., 2008).

Studies have also found that single mothers experience more distress, depressive symptoms, and more negative life events on average than married mothers (Iobst et al., 2009). For children, the likelihood of poor school performance, behavioral problems, and psychological distress are increased when they transition from a two-parent to a singleparent household structure (Hoffman, 2006; Jablonska \& Lindberg, 2007; Iobst et al., 2009). These findings support the benefits or a two-parent household and highlight the necessity of identifying influencers of marital satisfaction to promote healthier and happier marriages and families in order to decrease the rates of divorce. Measures of marital satisfaction can provide insight into those at risk for divorce, as married individuals who report low levels of marital satisfaction are more likely to have their marriage end in divorce (Gottman, 2014; Karney \& Bradbury, 1997).

Traditional family roles are changing across the country within families of all designs. As dual-income households are growing increasingly more normative, the more traditional roles of the family must evolve as well (Hill, Hawkins, Ferris, \& Weitzman, 
2001). When both parents in a family work outside of the home, balancing the responsibilities of an occupation and parenting roles becomes vital to functioning. Since children with special needs often attend more medical and therapy appointments than children without special needs, parents must be able to set aside time from their jobs and additional responsibilities to ensure that their children receive the services they require (Daire et al., 2011; Pickar \& Kaufman, 2015). For working parents, having a flexible job schedule may ease some of the worry or stress related to missing work in order to care for their children (Henly, Shaefer, \& Waxman, 2006; McNall, Masuda, \& Nicklin, 2009). In the instance that a parent has very low job flexibility, there may be times when they are unable to take their child to an appointment because of work demands and the fear of becoming unemployed (Allen, Johnson, Kiburz, \& Shockley, 2013). Even in singleincome households, having flexibility in the workplace may grant more freedom to take care of family needs and to support their spouse in caring for the children (Crettenden, Wright, \& Skinner, 2014).

With the additional time, money, and energy spent caring for a child with special needs, feeling supported by others is needed for the parents' mental and physical wellbeing. Parents who struggle with the responsibilities of their role as parent to a child with special needs can bring this stress into their intimate relationships and suffer from marital discord as well, which can lead to divorce (Holland \& McElwain, 2013). For marriages in general, being supported by a spouse is beneficial to both members of the couples' overall health (Priem, Solomon, \& Steuber, 2009). The perception that an individual has of how their spouse helps with parenting responsibilities may impact how connected they feel to their spouse in other aspects (Wieland \& Baker, 2010). 
Previous research has not explored all of the potential factors influencing the marital satisfaction of parents of children with special needs. There is a tendency to focus on how a child's behavior impacts family functioning and marital intimacy. While this is important to examine, as studies have shown that when children with special needs display more extreme or aggressive behaviors their parents report less satisfaction in their marriage, this places a certain degree of responsibility onto the child that is unfavorable (Smith \& Grzywacz, 2014; Starr, 1981). It is necessary to understand that all members of the family can influence each other (Bowen, 1978), however it is also essential to scrutinize more complex areas of parents' daily lives that may impact their marital relationship, as opposed to only causal influences. Examining external factors, such as workplace flexibility, and internal factors, such as perceptions of the other parent's support, may provide a broader view into the various influences that both members of the couple bring into their intimate relationship. Using the bioecological model as its guide, this research will examine how family influence operates within the marital relationship.

The purpose of this study is to examine the factors that influence the marital satisfaction of parents of children with special needs. Previous studies have investigated this topic on the surface by doing comparisons of the marital satisfaction of parents with and without children with special needs (Daire et al., 2011; Starr, 1981). These previous studies have attempted to answer a broad question of how these relationships are informed by the presence of a child with special needs existing within the fabric of the family. There is more to consider when it comes to the well-being of these families, however, and this study aims to expand upon the areas that have been examine while also digging deeper into the intricacies that influence how couples balance their marital 
intimacy in addition to their responsibilities as parents of children with special needs. Specifically, this study will consider how the factors of perceived job flexibility and perceived spousal support in parenting may inform marital satisfaction.

This study contributes to the literature in several key ways. Initially, this study aims to investigate factors influencing the marital satisfaction of couples with children with special needs, which have not been given enough attention in previous work. By exploring perceived job flexibility and perceived spousal support, this work may find novel information that could be of benefit to future studies regarding marital satisfaction and the prevention of divorce. With the rates of divorce for parents of children with special needs within the United States resting around 70-80\% (Sobsey, 2004), this study could help to inform marriage counselors and therapists of additional dynamics within the relationship that may be worth addressing in sessions with their clients in order to improve the quality of the marital relationship. Also, by examining the influence of job flexibility, this study may contribute to public policy regarding workers' rights and improvement in working conditions to bolster the work-life balance of employees. Finally, any limitations found within this research may be built upon and influence the direction that studies of this nature follow in the future.

\section{Definitions of Key Terms}

This list was created in order to provide a clear and concise interpretation of the key terms and theories utilized in this study:

1. Special Needs: An umbrella term used to describe a population meeting the following definition: 
"Any physical, developmental, mental, sensory, behavioral, cognitive, or emotional impairment or limiting condition that requires medical management, health care intervention, and/or use of specialized services or programs. The condition may be congenital, developmental, or acquired through disease, trauma, or environmental cause and may impose limitations in performing daily self-maintenance activities or substantial limitations in a major life activity. Health care for individuals with special needs requires specialized knowledge acquired by additional training, as well as increased awareness and attention, adaptation, and accommodative measures beyond what are considered routine" (Council on Clinical Affairs, 2012).

2. Marital Satisfaction: The general degree of happiness felt in a marriage in addition to the level of agreement or disagreement on critical issues faced by married persons (Priem et al., 2009). Measured in this study by using the Marital Adjustment Test (MAT).

3. Perceived Spousal Support in Parenting: The amount to which a person trusts in their partner's parenting capabilities and feels supported by their partner in the parenting process (Abidin \& Brunner, 1995; Holland \& McElwain, 2013). Measured in this study by using the Parenting Alliance Inventory (PAI).

4. Job Flexibility: The degree to which a worker feels that they have flexibility in the scheduling of work hours and in balancing family and work responsibilities (Rothausen, 1994). Measured in this study by using Rothausen's (1994) measure of job flexibility. R 
5. Bioecological Model of Human Development: Bronfenbrenner's (1994) theory that explains that human development is influenced by the multiple levels of interactions, either direct or indirect, that they encounter in their daily lives. It suggests that varying systems of environments that the individual is connected with can affect their development (Bronfenbrenner, 1994).

\section{Research Questions}

The purpose of conducting this research is to examine factors that influence the marital satisfaction of parents of children with special needs diagnoses, specifically the influences of perceived spousal support in parenting and job flexibility. The following questions will guide the direction of this study:

- Will marital satisfaction be higher in couples where one or both parents of a child with special needs have perceived job flexibility?

- Does the amount of perceived spousal support in parenting responsibilities impact the level of marital satisfaction of parents of a child with special needs?

- Does the amount of job flexibility one partner has influence the amount of perceived parental support from a spouse?

- Will perceived spousal support in parenting mediate the relationship between job flexibility and marital satisfaction for parents of children with special needs? 
These research questions were used to inform the creation of a survey instrument intended to measure the abovementioned factors. The data will be analyzed using the technique of linear regression and will be presented in the form of a mediation model. 


\section{CHAPTER II - MANUSCRIPT \\ Literature Review}

In the modern landscape of the United States society, there is a changing ideology about the institution of marriage. Daugherty and Copen (2016) found that increases in cohabitation, births outside of marriage, age at first marriage, and a decrease in fertility have contributed to changes in the normative family structure of the United States over the last 50 years. Other potential influencers, such as improvements towards gender equality, greater numbers of young people receiving higher education, and a weakened financial economy, may also be responsible for the evolution of ideas and traditions surrounding marriage (Fincham \& Beach, 2010). Additionally, the social acceptance of divorce, premarital intercourse, same-sex marriages, and cohabitation have significantly increased in recent times as the demographic structure of the US has also shifted (Copen, Daniels, \& Mosher, 2013; Daugherty \& Copen, 2016). There is even evidence to suggest the possibility of social networks having influence on which couples will divorce (McDermott, Fowler, \& Christakis, 2013).

Research has indicated that many people feel that when a couple cannot solve their marital issues, divorce may be the best option for resolution (Daugherty \& Copen, 2016). In fact, one in three adults agree that marriage has not worked for most of the people they know in their lives (Daugherty \& Copen, 2016). Regardless of common beliefs or current norms, the life events of both marriage and divorce can both be considered very common events among families in current society (Kazdin, 2000). A Center for Disease Control and Prevention (CDC) survey from 2014 reported that the rate of marriage for the year was 6.9 per 1,000 total population, with an estimate of 2,140,272 
marriages country wide, and the American Psychological Association reported that over $90 \%$ of individuals will marry before the age of 50 (Kazdin, 2000; National Center for Health Statistics, 2016). Alternatively, the CDC reports that the divorce rate is approximately 3.2 per 1,000 total population and the APA estimates that 40 to 50 percent of marriages will result in divorce, with rates for successive divorces being even greater (Kazdin, 2000; National Center for Health Statistics, 2016).

Divorce rates are significantly higher among parents of children with special needs (Sobsey, 2004; Wymbs et al., 2008). This difference is pronounced among parents of children with attention-deficit/hyperactivity disorder (ADHD) and autism spectrum disorder (ASD) compared to the general population (Hartley et al., 2010; Pickar \& Kaufman, 2015;Wymbs et al., 2008). Compared to parents of children without ADHD, parents of children with ADHD have been found to have more fights, utilize less positive and more negative statements when discussing parenting, and report lower levels of satisfaction in marriage (Wymbs et al., 2008).

\section{Bioecological Systems Model}

Bronfenbrenner's (1994) bioecological model explains that the development of an individual is influenced by the multiple levels of interactions, either direct or indirect, that they encounter in their daily lives. The theory suggests that varying systems of environments that the individual is connected with can affect their development (Bronfenbrenner, 1994; Rosa \& Tudge, 2013). These levels, or systems, are as follows: the microsystem, the mesosystem, the exosystem, the macrosystem, and the chronosystem. 


\section{Connecting Existing Literature to Bioecological Systems Model}

The bioecological model states that a person is influenced by various levels of interaction across many settings. This is in agreement with the main idea of the study, which purposes that the marital satisfaction a couple experiences is shaped by the various internal and external environments within which they live their lives. Existing literature supports the connections between the main components of the current study and the various levels of the bioecological systems model, most notably those of the microsystem and exosystem. In line with the exosystem is the idea that the workplace flexibility of a parent may influence the amount of time they are able to have at home caring for their child. In terms of the microsystem, the amount of time they have at home to provide parenting support will then likely impact how much support their spouse feels in the parenting duties.

\section{Microsystem}

A married couple represents a microsystem, an intimate relationship within their immediate environment, where the individuals effect the continuing development and growth of one another (Bronfenbrenner, 1994). Using the lens of the bioecological model, it is understood that the individuals in a marriage hold influence over each other. Spending time together has been found to be one of the key factors of high marital satisfaction (Russell-Chapin, Chapin, \& Sattler, 2001), and is a way in which both members of the microsystem directly interact with one another and develop their perceptions about the quality of the relationship. However, spending time together can be especially strained in families with children with special needs. Parents of children with special needs spend more time taking their children to medical and therapy appointments 
and more time providing direct supervision to their children, which can reduce the amount of quality time spent with their spouse (Daire et al., 2011; Russell-Chapin et al., 2001).

While being able to actively interact in a positive manner with a spouse may improve the relationship between members of a microsystem, the unavailability or absence of this person from the microsystem is likely to detract from the quality of the relationship. Individuals who feel unsupported or disconnected from their spouse may even transfer this dissatisfaction to their roles as parents (Ato et al., 2015; Kersh et al., 2006), whereas couples who experience higher levels of marital satisfaction tend to be more supportive and involved as parents (Ato et al., 2015). This suggests that the connections and interactions experienced within the microsystem of a family strongly effect the well-being of all of its members.

Children may be at a high risk for anxiety, aggression, and behavioral problems if they are subjected to high conflict between married parents (Morrison \& Coiro, 1999). In fact, some research has found that exposure to parental conflict can be more detrimental to children than the loss of a parent through divorce or death (Jekielek, 1998; Morrison \& Coiro, 1999). Unproductive parenting methods, a lack of warmth and attention to the child, and inconsistent discipline techniques within the parent-child dyad have also been attributed to marital discord among parents (Peris, Goeke-Morey, Cummings, \& Emery, 2008). In the instance of a divorce, both children and parents within the microsystem are impacted by it. Couples who divorce tend to have "a lower standard of living, have less wealth, and experience greater economic hardship than do married individuals" (Forste \& Heaton, 2004, p. 99). Greater rates of psychological distress, illnesses, alcohol use, and 
decreased emotional health are also found in divorced individuals more often than in married individuals (Forste \& Heaton, 2004). For children experiencing the divorce of their parents, there is a risk of behavioral, emotional, and mental and physical health problems in response to the division of the systems within their family (Fergusson et al., 2014; Weaver \& Schofield, 2015; Woody, 2009).

\section{Exosystem}

The exosystem indicates that an individual's development can be influenced by an external source where the individual is not present (Rosa \& Tudge, 2013). In terms of the current study, it is suggested that the flexibility of a parent's workplace can impact the resources available to the children and spouse of an individual. Balancing time and schedules is necessary in any family, however, in a family with children with special needs, the need for flexibility can be greater in order to provide the children with services they require. If parents are unable to take time off of work due to schedule rigidity or financial concern, they may be faced with choosing between their job and their children.

Due to increased hospital visits, parents of children with special needs have additional time and finance burdens to juggle. As many children with special needs require individualized care and services that children without special needs do not (e.g., respite care, assistive devices, and specialized medical professionals), parents of children with special needs may face challenges in meeting these extra requirements (Daire et al., 2011). Daire et al. (2011) found "the mean number of healthcare visits in a six-month period for children with special needs was 50.47 compared to 0.29 for children without special needs" (p.183). This increased financial burden can be as much as three times higher than the costs of caring for a child without special needs and may also strain the 
marital relationship if one parent must stay at home to care for the child, or if the family already had financial struggles before the birth of the child (Daire et al., 2011; Dobson \& Middleton, 1998). The impact of this conflict between parent and occupation represents circumstances that effect the child and the spouse even though they are not present, which is depicted within the exosystem of the bioecological systems model. If the working parent(s) do not have flexibility in the workplace they may risk missing income and losing their job and insurance, which would drastically impact available family resources. Even still, these parents may miss out on opportunities to take their children to therapies they may require.

\section{Children with Special Needs}

The number of children who have a special needs diagnosis in the United States gives credence to the necessity of studying the family lives of these such children. More than 6 million children between the ages of three and 21 (about $13 \%$ of all public school students) required special education courses for the 2013-2014 school year (National Center for Educational Statistics, 2016). Within these same numbers, 35\% of students had a specific learning disability, $21 \%$ had a speech or language disability, $13 \%$ were classified as having 'other health impairments,' $8 \%$ had a diagnosis of autism, and the remaining conditions reported occurred within $7 \%$ or less of the students with special needs (National Center for Educational Statistics, 2016). These developmental disabilities include deficiencies in language, learning, and physical and behavioral functioning, which arise in early development and likely last through the individual's entire life (Centers for Disease Control and Prevention, 2015). One study found that in the major 
metropolitan areas of the United States, the dominant disability type reported in young children is that of cognitive difficulty, defined as an acute problem with concentrating, decision making, and memory (Brault, 2011).

Based on these statistics, it is evident that many children require additional services and accommodations beyond what is typically provided to children without a special needs diagnosis. Additionally, the families working to provide this extra care for their children within the home face more stress and financial strain then families with children without developmental concerns (Thurston et al., 2011). Understanding the challenges that families face when raising a child with special needs can help researchers and practitioners create effective treatment and therapy plans that benefit the individual child, the parenting unit, and the family as a whole.

\section{Perceived Spousal Support in Parenting}

Feeling supported in the parenting role is essential for mothers and fathers of children of all functioning and ability levels (Cohen, Zeedyk, Tipton, Rodas, \& Blacher, 2016). This support reduces stress for the individual parents, improves family functioning, and creates consistency for the children within these families (Holland \& McElwain, 2013). Parents who feel supported by one another are likely to perform better in their roles as parents and utilize effective and nurturing parenting styles that are in agreement with how both parents believe the children should be reared (Bristol et al., 1988; Wieland \& Baker, 2010). The feeling of being supported can even reduce the risk of depression in parents and can indicate high levels of marital satisfaction (Wieland \& Baker, 2010). 
As Bristol et al. (1988) found, expressive support from a spouse is a strong predictor of the quality of parenting that the child will receive. Expressive support is considered to be a person's perception of how appreciated, understood, included, and loved they feel by their spouse (Bristol et al., 1988). This finding of the importance of spousal support was observed for parents of children with special needs as well as for parents of children without special needs (Bristol et al., 1998; Wieland \& Baker, 2010). This perception of support is informed by how the parent perceives the other's involvement, how the other behaves, and the satisfaction felt within the current relationship (Priem et al., 2009). Parents who trust one another to provide the best level of care for their child are likely to feel higher amounts of marital love, and those with higher levels of marital connection are likely to trust the other partner in the parenting position more (Belsky, Putnam, \& Crnic, 1996; Holland \& McElwain, 2013). This finding is also true in the reverse, whereas couples who have highly distressed marriages are likely to engage ineffectively in their parenting practices (Belsky et al., 1996; Holland \& McElwain, 2013).

Considering the notion that the amount of support a parent feels influences the quality of parenting that a child will receive, it is imperative to examine how each parent is interpreting the involvement of their co-parent. Measuring perceived spousal support in parenting can be accomplished by self-report measures which allow the participant to describe how much and in what ways their spouse helps with parenting responsibilities.

\section{Perceived Job Flexibility}

Job flexibility has been defined in various ways in past studies. For some, the concept of job flexibility has been described as the methods that human resource 
departments utilize in order to help workers balance work and non-work responsibilities, and others see it as the amount of choice that a worker has in designing and altering central facets of their working roles (Allen et al., 2013; Bal \& De Lange, 2015; Hill et al., 2008). In this current study, the term will be defined as it relates to time, and can be thought of as places of work "allowing employees to have flexible schedules that enable them to better manage work and personal or family life" (Galinsky, Sakai, \& Wigton, 2011, p. 142-143).

For families with children, having some degree of flexibility in the workplace may contribute greatly to family functioning. While it is necessary for most families in modern society to have at least one employed parent, many families now have both parents working outside of the home (Hill et al., 2001). The income is vital for family stability, however, when children are occasionally sick or have chronic conditions, someone needs to be able to stay home to care for them or take them to the doctor. Unfortunately, this is not always possible, as some families cannot afford to take unpaid time off, which then leaves the parents depending on others to help care for their children in the interim.

In dual-earner households, the parents may need to rely on child care centers to care for their children during work hours. Child care facilities typically hold standard hours of operation and may not be able to accommodate parents on days where they need to work overtime to catch up on missed work or to get ahead in their duties (Press \& Fagan, 2006). This can create conflict, as parents may have to negotiate with each other to determine who will be responsible for picking up the children, as well as finding leniency in their working hours if they are needed to attend to the children (Press \& 
Fagan, 2006). However, if parents are able to take turns or compromise on when each parent needs to be available for child care so that the other parent can work, the individuals may experience higher levels of perceived parenting support (Press \& Fagan, 2006).

Having flexibility in the workplace can also improve the job satisfaction, work performance, and health of the employee (Michel \& Michel, 2015; Vandello, Hettinger, Bosson, \& Siddiqi, 2013). For those who work nonstandard hours, work schedules which are not created around the needs of their family can increase stress, increase work-family role conflict, reduce the amount of time spent with children, and decrease marital satisfaction (Henly et al., 2006; McNall et al., 2009). As of 2003, nearly 40 percent of American workers worked nonstandard, daytime hours - making the need to create more schedule flexibility that takes the individual into account even more necessary (Henly et al., 2006).

Final Conclusions about Existing Literature

Previous literature has examined many factors that impact marital satisfaction and highlight risk factors for divorce or marital discord (Balderrama-Durbin, Snyder, \& Balsis, 2015; Daugherty \& Copen, 2016; Gottman, Coan, Carrere, \& Swanson, 1998; Holland \& McElwain, 2013; Kazdin, 2010; Wymbs, 2008). The families of children with special needs have also been observed as the subjects of this research, with a focus on the unique dynamics of the relationships between these children and their parents (Daire et al., 2011; Hartley et al., 2010; Pickar \& Kaufman, 2015). Considerations of spousal support in parenting practices and the schedule flexibility of workplaces have likewise been acknowledged in studies concerning job, life, and marital satisfaction of individuals 
(Belsky et al., 1996; Bristol et al., 1988; Hill et al., 2001; Michel \& Michel, 2015; Vandello et al., 2013; Wieland \& Baker, 2010), however, there is a deficiency in the research concerning how interconnected the concepts of perceived job flexibility and spousal support in parenting may be to the overall marital satisfaction of parents with children with special needs. The current study aims to fill this gap in the literature by examining how the role of perceived spousal support in parenting mediates the relationship between perceived job flexibility and the marital satisfaction of parents with children with special needs.

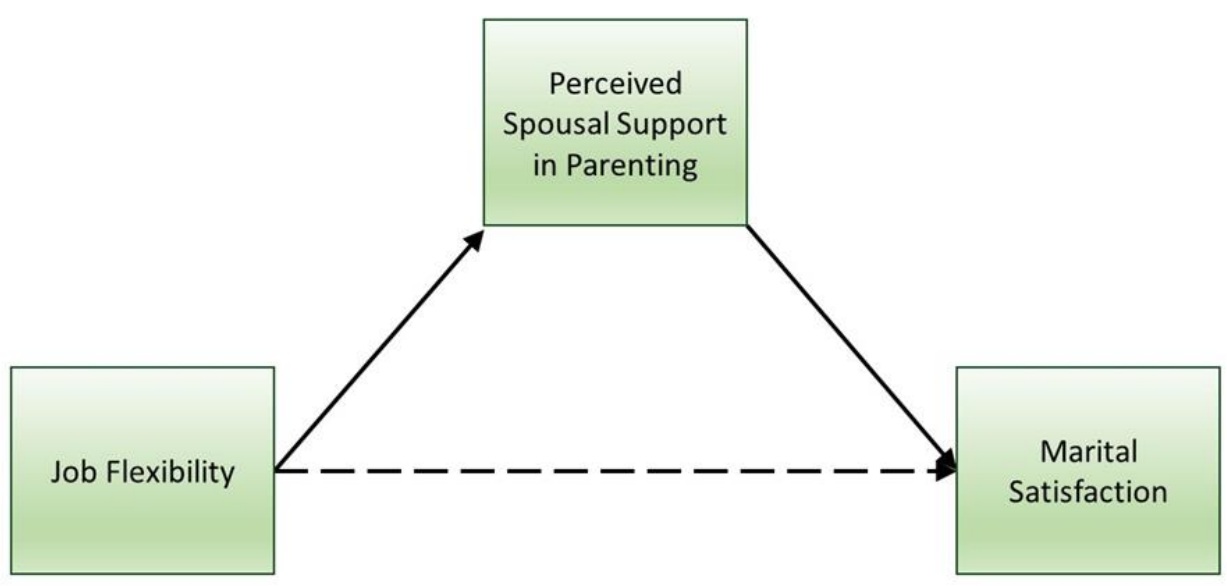

Figure 1. Hypothesized mediation model of the relationship between job flexibility, perceived spousal support in parenting, and marital satisfaction.

\section{Current Study}

The marital satisfaction of parents who have children with special needs has been examined as a subject of interest by many family researchers (Daire, Munyon, Carlson, Kimemia, \& Mitcham, 2011; Kersh, Hedvat, Hauser-Cram, \& Warfield, 2006; Smith \& Grzywacz, 2014). As children with special needs tend to require more unique care than children without special needs, different dynamics may be observed among their families. 
Past research has focused on the interaction between the couple as it relates to their child's behavior (Kersh et al., 2006). While this is valuable to study, as children with behavioral issues do influence the rest of the family's functioning (Smith \& Grzywacz, 2014; Starr, 1981), there are other aspects that should be examined as well. With prevalence rates indicating that about $13 \%$ of children ages three to 17 years have a special needs diagnosis (National Center for Educational Statistics, 2016), there is a significant population of families who may benefit from research into marital satisfaction as it pertains to the parents of children with special needs.

Studies have found that single mothers experience more distress, depressive symptoms, and more negative life events on average than married mothers (Iobst et al., 2009). For children, the likelihood of poor school performance, behavioral problems, and psychological distress are increased when they transition from a two-parent to a singleparent household structure (Hoffman, 2006; Jablonska \& Lindberg, 2007; Iobst et al., 2009). These findings support the benefits or a two-parent household and highlight the necessity of identifying influencers of marital satisfaction to promote healthier and happier marriages and families in order to decrease the rates of divorce. Measures of marital satisfaction can provide insight into those at risk for divorce, as married individuals who report low levels of marital satisfaction are more likely to have their marriage end in divorce (Gottman, 2014; Karney \& Bradbury, 1997).

Traditional family roles are changing across the country within families of all designs. As dual-income households are growing increasingly more normative, the more traditional roles of the family must evolve as well (Hill, Hawkins, Ferris, \& Weitzman, 2001). When both parents in a family work outside of the home, balancing the 
responsibilities of an occupation and parenting roles becomes vital to functioning. Since children with special needs often attend more medical and therapy appointments than children without special needs, parents must be able to set aside time from their jobs and additional responsibilities to ensure that their children receive the services they require (Daire et al., 2011; Pickar \& Kaufman, 2015). For working parents, having a flexible job schedule may ease some of the worry or stress related to missing work in order to care for their children (Henly, Shaefer, \& Waxman, 2006; McNall, Masuda, \& Nicklin, 2009). In the instance that a parent has very low job flexibility, there may be times when they are unable to take their child to an appointment because of work demands and the fear of becoming unemployed (Allen, Johnson, Kiburz, \& Shockley, 2013). Even in singleincome households, having flexibility in the workplace may grant more freedom to take care of family needs and to support their spouse in caring for the children (Crettenden, Wright, \& Skinner, 2014).

With the additional time, money, and energy spent caring for a child with special needs, feeling supported by others is needed for the parents' mental and physical wellbeing. Parents who struggle with the responsibilities of their role as parent to a child with special needs can bring this stress into their intimate relationships and suffer from marital discord as well, which can lead to divorce (Holland \& McElwain, 2013). For marriages in general, being supported by a spouse is beneficial to both members of the couples' overall health (Priem, Solomon, \& Steuber, 2009). The perception that an individual has of how their spouse helps with parenting responsibilities may impact how connected they feel to their spouse in other aspects (Wieland \& Baker, 2010). 
Previous research has not explored all of the potential factors influencing the marital satisfaction of parents of children with special needs. There is a tendency to focus on how a child's behavior impacts family functioning and marital intimacy. While this is important to examine, as studies have shown that when children with special needs display more extreme or aggressive behaviors their parents report less satisfaction in their marriage, this places a certain degree of responsibility onto the child that is unfavorable (Smith \& Grzywacz, 2014; Starr, 1981). It is necessary to understand that all members of the family can influence each other (Bowen, 1978), however it is also essential to scrutinize more complex areas of parents' daily lives that may impact their marital relationship, as opposed to only causal influences. Examining external factors, such as workplace flexibility, and internal factors, such as perceptions of the other parent's support, may provide a broader view into the various influences that both members of the couple bring into their intimate relationship. Using the bioecological model as its guide, this research will examine how family influence operates within the marital relationship.

\section{Research Questions}

The purpose of conducting this research is to examine factors that influence the marital satisfaction of parents of children with special needs diagnoses, specifically the influences of perceived spousal support in parenting and job flexibility. The following questions will guide the direction of this study:

- Will marital satisfaction be higher in couples where one or both parents of a child with special needs have perceived job flexibility? 
- Does the amount of perceived spousal support in parenting responsibilities impact the level of marital satisfaction of parents of a child with special needs?

- Does the amount of job flexibility one partner has influence the amount of perceived parental support from a spouse?

- Will perceived spousal support in parenting mediate the relationship between job flexibility and marital satisfaction for parents of children with special needs?

These research questions were used to inform the creation of a survey instrument intended to measure the abovementioned factors. The data will be analyzed using the technique of linear regression and will be presented in the form of a mediation model.

\section{Hypotheses}

The reviewed literature has informed the creation of the following hypotheses:

H1. Marital satisfaction levels will be higher for individuals that report that one or both parents have perceived job flexibility.

H2. Marital satisfaction levels will be higher for individuals that report higher levels of perceived spousal support in parenting responsibilities.

H3. Perceived spousal support in parenting responsibilities will be higher for individuals that report that one or both parents have perceived job flexibility.

H4. Perceived spousal support in parenting responsibilities will mediate the relationship between perceived job flexibility and marital satisfaction. 


\section{Methods}

The purpose of conducting this quantitative research was to examine factors that influence the marital satisfaction of parents of children with special needs diagnoses, specifically the influences of perceived spousal support in parenting and job flexibility. A self-report survey questionnaire was used to collect data from married participants of at least 18 years of age, who were married and had a child with a special needs diagnosis. Data was examined using linear regression and a mediation model. After presenting participants with a consent form and verifying that they meet the required criteria, the participants completed an online questionnaire which addressed demographic information, marital satisfaction, spousal perceptions of parenting support, and job flexibility.

Sample

Individuals at least 18 years of age who are married and have a child or children with special needs were the target population of this study. This survey aimed to include over 100 participants as an appropriate sample size for obtaining a low margin of error for a study of this nature (Burmeister \& Aitken, 2012). This study was available to participants meeting the aforementioned criteria without any stipulations on gender, sex, sexual orientation, race, ethnicity, or religious beliefs.

The survey was distributed electronically and was hosted through the Qualtrics web server. As this survey will existed online, it was shared with participants via social media websites (Facebook.com, Reddit.com) and through the email newsletters of the University of Southern Mississippi (USM) and the National Council on Family Relations (NCFR). Social media groups related to special needs and parenting were contacted 
specifically. Utilizing the internet as the medium for distribution allowed for the survey to be administered with a great deal of time flexibility, at a quick rate, with low cost, and with the potential to obtain a large sample size (Benfield \& Szlemko, 2006; Best, Krueger, Hubbard, \& Smith, 2001). This study relied on snow-ball sampling and word of mouth in order to reach the desired number of participants. Participants were able to complete the survey at their own leisure, were not hindered by waiting for a mail-in survey, and experienced no financial deficits outside of their pre-existing expenses for internet service.

As this survey was be distributed to human participants, conducting the study in an ethical manner was mandatory. The first step in protecting the subjects was to make them aware of any possible risks associated with participating in the study. Participants were advised to consider these minor risks of emotional discomfort in the consent agreement before entering into the survey, and they were also reminded that they could leave the survey at any time if they felt uncomfortable. Participants were able to skip any question that they did not wish to answer. Those who choose to complete the survey were reminded that their participation was voluntary and that they could choose to exit the survey at any time. Additionally, resources for counseling or support for a child with special needs were provided at the beginning and the conclusion of the survey.

Another consideration in providing ethical treatment was the degree of privacy that the participants would receive. All participants were informed of the purpose of the survey, their rights in participating, and the confidentiality that they could expect. Participants did not provide any identifiable information and all data received was linked with a number instead of any name or email address. After the study was completed, all 
information that was collected online was transferred to a data analysis program on a password protected computer. This study followed all guidelines set by the University of Southern Mississippi’s Institutional Review Board (IRB).

\section{Measures}

This study was conducted in the format of a self-report, survey questionnaire. The introduction of the survey provided participants with a consent agreement and a prompt to verify that they were at least 18 years of age. Participants who signified that they were not at least 18 years of age were taken to the end of the survey immediately. The consent form was electronically displayed and agreed to before the individual could begin the questionnaire. The consent form informed the participants that the data they provided would be kept confidential, that participating in the survey was completely voluntary, and that they could leave the survey at any time.

Demographic Information. Participants were asked to indicate their current location (country/state), sex, ethnicity, race educational level, age, length of current marriage, and income. These questions were similar in format to items on current U.S. Census questionnaires can be found in Appendix A. The purpose of collecting information about the participant's location, sex, ethnicity, race, education level, age, length of current marriage, and income was to help determine potential confounding variables that may influence the interpretation of results. Data on these descriptors could also be helpful in spotting trends recognized in previous research. For example, families with children with special needs tend to spend more money on care for their child than those with children without special needs (Thurston et al., 2011). Differences in levels of income could impact how much stress each family feels when meeting these needs and 
may prove to be notable in interpreting the results of this survey. Additionally, many previous studies reflect the viewpoint of mothers of children with special needs (Blacher et al., 1997; Hoare, Harris, Jackson, \& Kerley, 1998), so being able to determine the sex of the participant may also influence data interpretations.

Additionally, participants were asked to provide non-identifiable information about their child or children. Participants were asked how many children are living in the home, how many children with a special needs diagnosis they have, the age of their child with special needs, and the specific diagnosis of their child with special needs.

Participants were asked how many medical and therapy appointments their child attended in the last 30 days, the number of hours spent at said appointments in the last 30 days, and the approximate amount of appointments in which the participant joined their child. For participants with more than one child with a special needs diagnosis, they were able to answer the aforementioned questions for each child. Just as the demographic mentioned above, these descriptive questions could also be helpful in recognizing trends seen in previous studies. For example, parenting has been shown to be more stressful within families who have children who are more dependent or require more medical and therapy appointments than children who require less intervention (Algood, Harris, \& Hong, 2013; Hodapp, Ly, Fidler, \& Ricci, 2001). Also, within families raising a child with special needs, there is less time for parents to spend together as marital couple (Wayne \& Krishnagiri, 2005), so there may be a relationship between marital satisfaction and time spent taking children to appointments.

Measures of Marital Satisfaction. Martial satisfaction was measured using the Marital Adjustment Test (MAT), which consists of 15 items (Locke \& Wallace, 1959). 
The MAT questions were designed to "assesses general happiness with a marriage, as well as the extent of agreement or disagreement between partners on issues such as finances, recreation, affection, friends, sex, philosophy of life, and dealing with in-laws" (Priem et al., 2009). This 15 item measure consisted of 7 multiple choice questions, 1 question which used a Likert scale to prompt the participant to indicate on a dotted line where they would rate their current happiness in their marriage from very unhappy to perfectly happy, and 8 questions which used a 6-point Likert scale to rate the degree to which their spouse and they agree on various topics, with possible responses ranging from always agree to always disagree. Respondents received scores which varied between the items, with a higher overall score representing a higher degree of marital satisfaction (Ato et al., 2015; Saxbe et al., 2008). This measure was chosen because of its high internal reliability (.90) and the high frequency with which it has been utilized in previous work, such as that of Ato et al., (2015) and Saxbe et al., (2008). An example of the survey instrument can be found in Appendix C.

Measures of Perceived Spousal Support in Parenting. Perceived spousal support in parenting was measured using the Parenting Alliance Inventory (Abidin \& Brunner, 1995). This consisted of 20 items intended to assess the trust the respondent felt in their partner's parenting capabilities, as well as the support they felt that they received from their partner in the parenting process (Abidin \& Brunner, 1995; Holland \& McElwain, 2013). The items were on a 5-point Likert scale and participants selected how much they agreed with a statement within the range of choices, with 1 indicating strong disagreement and 5 indicating strong agreement; with a higher score being associated with higher perceived support. This measure was chosen due to the high reliability (.97) 
and frequency of use in previous studies, with examples including the work of Abidin \& Brunner (1995) and Holland \& McElwain (2013). An example of the survey instrument can be found in Appendix C.

Measures of Job Flexibility. Participants were asked to identify their current employment status, their current occupation, and the average amount of hours worked per week. If they were unemployed, questions pertaining to their own workplace were omitted. Additionally, participants were asked to identify their spouse's current employment status, their spouse's current occupation, and the average amount of hours their spouse works per week. If their spouse was unemployed, questions pertaining to their spouse's workplace were omitted. Participants were asked to rate their perception of their workplace's flexibility if they indicated that they were employed. Participants were asked to rate their perception of their spouse's workplace's flexibility if they indicated that their spouse was employed.

Job flexibility of the participant was ascertained using Rothausen's (1994) measure of job flexibility. The measure consisted of a 5-point Likert scale in which the participants indicated their satisfaction with the 5 presented statements on a scale ranging from 1 (strongly dissatisfied) to 5 (strongly satisfied); with a higher score indicating a higher level of perceived job flexibility. The statements were as follows: "1. The extent to which management accommodates family responsibility and needs without negative consequences, 2 . The opportunity to perform your job well and yet be able to perform home-related duties adequately, 3 . The ease of getting time off for family as needed, 4 . The opportunity to do part-time or flex-time work without being penalized, and 5. The amount of flexibility in work scheduling" (Rothausen, 1994). In the event that both the 
participant and their spouse were employed, the scores from the participant and their spouse on the job flexibility measure were averaged together to create one numeric response. This measure was chosen due to the high reliability (.87) and frequency of use in previous studies, with examples including the work of Rothausen (1994) and Michel \& Michel (2015). An example of the survey instrument can be found in Appendix C.

Scoring Measures. Each section of the given survey was calculated according to the affiliated guidelines from which the section was derived. Marital satisfaction was measured using the complete, 15-item MAT. The data derived from this portion was coded and scored using the specific rubric of the MAT to find an averaged response indicating the level of marital satisfaction felt. Job flexibility was measured using Rothausen's (1994) measure of job flexibility. The data accumulated from this portion of the survey was coded dichotomously to represent participants' being "satisfied with job flexibility" or "dissatisfied with job flexibility/" An average numbered response to indicate the level of flexibility the individual experienced in their workplace, as well as the amount of job flexibility that their spouse received in their respective workplace, was averaged and used to represent with the individual perceived having or not having job flexibility. Perceived parental support of a spouse was measured using the complete version of the 20-item PAI. The data acquired from this portion of the survey was calculated into an average score of perceived parental support from a spouse. The data was organized and coded in the most efficient manner possible in order to produce concise results. 


\section{Procedures}

This study was comprised of a self-report survey measure designed to examine demographic information, marital satisfaction, spousal perceptions of parenting support, and job flexibility of parents of children with special needs diagnoses. The questionnaire was distributed online so that participants could complete the survey in any location or at any time that was convenient for them. The items on the questionnaire were aimed towards addressing the research questions and were conducted in an ethical manner.

There was a total of 75 items on the questionnaire when the respondent and their spouse were both employed and had only one child with a special needs diagnosis. If either the participant or their spouse were reported to be unemployed, the participant did not answer job flexibility questions for the unemployed person, and received 66 questions. In the event that both the participant and their spouse were reported to be unemployed, the participant did not answer any job flexibility questions, and only received 57 questions. For participants who had more than one child, they answered 9 more questions for each additional child reported. In the instance that the participant did not live in the United States, they did not have to indicate which state they live in, and therefore had 1 less question to answer.

Consent Procedure. The first page of the survey contained the consent agreement, which participants agreed to in order to complete the survey. Participants were informed that the survey was voluntary, that they could leave the survey at any time, and that they did not have answer any questions which caused them any unease. By agreeing to continue to the survey, participants were also certifying that they were at least 18 years of age. Within the consent form, links to websites that may be resources for participants 
were provided in the circumstance that the participant required counseling or additional information.

Survey Procedure. Participants began the survey after indicating that they had reviewed the consent form and verified that they were at least 18 years old. The first section of the survey contained questions that recorded demographic information, including the following: state/country of residence, sex, ethnicity, race, educational level, age, and income. The next section asked about employment status of the participant and of the spouse of the participant. If participants were not employed, or if their spouse was not employed, skip logic was utilized in the survey program to avoid the participants being prompted to answer questions which did not pertain to them. Following employment, participants completed the marriage portion of the questionnaire. After indicating the length of their current marriage, participants completed the MAT. Once this section was completed, participants were directed to the section regarding children and parenting.

Participants indicated how many children they had and then answered whether they had any children with special needs. If the participant had a child with special needs, they were prompted to enter information concerning age of the child and therapies and appointments attended. The participant was able to enter the information for multiple children with special needs as necessary. The participant was then prompted to complete the PAI with their child/children with special needs in mind. If the participant did not have a child with special needs, the questions regarding appointments and therapies were skipped, as well as the PAI measure. This concluded the survey and the participant was 
thanked for contributing. Links for the supplemental resources that were on the consent form were then also provided at the end of the survey.

Data was collected from the Qualtrics survey hosting website and was downloaded to IBM SPSS Statistics 24 for analysis. There was no personally identifying information to link participants to their surveys and all entries were represented by numbers. All data was password protected in an additional effort to ensure confidentiality. The recorded data from the surveys was stored on a password protected computer after the completion of the survey. Additionally, the link to the online survey and all online data was deleted after all information had been transferred to the analysis program.

\section{Analysis of data}

The collected data from this study was largely quantitative in nature. All demographic information was organized and examined through descriptive statistical analysis. Data pertaining to marital satisfaction, perceived spousal support in parenting, and job flexibility were analyzed and interpreted through the mediation model and linear regression in order to address the proposed research questions. Connections between the variables and the influences they hold over one another were examined.

Descriptive Statistical Analysis. Data collected from the demographic section of the survey was interpreted though descriptive statistical analysis. Descriptive statistics from all study variables were reviewed to observe how data was distributed across the sample. Additionally, the descriptive statistics were used as control variables as necessary in completing further analyses. 
Correlations. Correlations among study variables were explored to identify potential associations. Connections between perceived job flexibility, perceived spousal support in parenting, and marital satisfaction were examined before imploring multiple regression and mediation. Additionally, descriptive variables, such as sex, working hours per week, and number of children with a special needs diagnosis, were analyzed with factors such as perceived job flexibility, marital satisfaction, and perceived spousal support in parenting, to determine any correlation.

Multiple Regression Analysis. Multiple regression was used to associate marital satisfaction with job flexibility and spousal support in parenting, while controlling for demographics. This method of analysis was utilized to examine whether marital satisfaction levels could be predicted based on perceived job flexibility and perceived spousal support in parenting. Multiple regression was also employed as necessary to determine the value of any other variables of interest within the dataset.

Mediation Model Analysis. The data collected during this study was analyzed through a mediation model which suggested that perceived parental support of a spouse mediates the relationship between job flexibility and marital satisfaction (see Figure 1). The mediation model analysis consisted of four steps which had to be followed in order to determine an indirect association between perceived job flexibility and marital satisfaction through perceived spousal support in parenting.

The first step required that the causal variable was correlated with the outcome variable (Baron \& Kenny, 1986; James \& Brett, 1984; Judd \& Kenny, 1981). Level of job flexibility was observed as it related to marital satisfaction. These variables had to be related in order to continue to the next step. The second step indicated that the causal 
variable was correlated with the mediator (Baron \& Kenny, 1986; James \& Brett, 1984; Judd \& Kenny, 1981). Level of job flexibility was examined as it relates to perceived spousal support in parenting. These variables must be correlated in order to continue the analysis.

The third step required that the mediator had an effect on the outcome variable (Baron \& Kenny, 1986; Judd \& Kenny, 1981). Perceived spousal support in parenting was observed as it relates to marital satisfaction. These variables should be correlated, however the final step was crucial in order to determine and level of causality. The fourth step required that the mediating variable be shown to completely mediate the relationship between the other two variables (Baron \& Kenny, 1986; James \& Brett, 1984; Judd \& Kenny, 1981). Perceived spousal support in parenting was examined as it influences the relationship between job flexibility and marital satisfaction. Following completion of these analyses, the results were reviewed in order to ensure that all research questions were addressed and all protocol was followed accurately. If the mediation hypothesis was correct, the link between perceived job flexibility and marital satisfaction would be nonsignificant when spousal support in parenting was in the model.

\section{Results}

Initially, 128 responses were obtained for the survey, however after removing responses that provided no legitimate contribution to the designed measure (responses that only reported demographic information before exiting the survey), there were 102 viable responses remaining for data analyses. Responses that were removed included submissions where only consent or only demographic questions were answered. As there were no forced-response questions on the survey, participants were able to skip questions 
that they felt uncomfortable or unwilling to answer. In the event that a participant occasionally skipped a question, those responses were not considered in the analyses, however all other questions were calculated in the analyses as per protocols. Information on missing data will be addressed measure by measure in the following sections.

\section{Demographics}

Of the 102 participants, $94.1 \%(n=96)$ were female and $5.9 \%(n=6)$ were male, as seen in Table 1 . When indicating age, $2 \%(n=2)$ of participants were between $18-24$ years old, 36.3\% $(n=37)$ were between 25 - 34 years old, 39.2\% $(n=40)$ were between 35 - 44 years old, $19.6 \%(n=20)$ were between 45 - 54 years old, $2.9 \%(n=3)$ were between 55 - 64 years old. Most of the participants in this sample were between the ages of 25 - 54 years old $(S D=.861)$. For ethnicity, $8.9 \%(n=9)$ of participants reported Hispanic or Latino, 91.1\% $(n=92)$ of participants reported not Hispanic or Latino, and one participant did not report their ethnicity. For race, $1 \%(n=1)$ of participants indicated Black or African American as their race, $4 \%(n=4)$ of participants indicated Asian or Asian American as their race, 94.9\% $(n=94)$ of participants indicated White as their race, and three participants did not disclose their race.

When addressing education, $2.9 \%(n=3)$ of participants reported an education level of less than $12^{\text {th }}$ grade, $3.9 \%(n=4)$ of participants obtained high school diploma, $19.6 \%(n=20)$ of participants attended some college/university or technical school with no degree, $10.8 \%(n=11)$ of participants obtained an Associate's degree, $40.2 \%(n=41)$ of participants held a Bachelor's degree, $16.7 \%(n=17)$ of participants obtained a Master's degree, and 5.9\% $(n=6)$ of participants held a professional degree beyond a Bachelor's degree/Doctorate (for example: MD, DDS, PhD, JD, LLB, DVM). For yearly 
income levels, $13.1 \%(n=13)$ of participants declared $\$ 20,000$ - $\$ 40,000,13.1 \%(n=13)$ of participants declared $\$ 40,000$ - $\$ 60,000,24.2 \%(n=24)$ of participants declared $\$ 60,000$ - $\$ 80,000,14.1 \%(n=14)$ of participants declared $\$ 80,000$ - $\$ 100,000,25.3 \%(n$ $=25)$ of participants declared $\$ 100,000-\$ 150,000,10.1 \%(n=10)$ of participants declared over $\$ 150,000$, and three participants did not indicate their income level. Most of the participants in this sample reported a yearly income level of $\$ 60,000$ - $\$ 100,000$ $(S D=1.56)$.

In terms of location, $95.6 \%(n=86)$ of participants were in the United States (from 31 different states), 3.3\% ( $n=3)$ of participants were in Canada, $1.1 \%(n=1)$ of participants were in the United Kingdom, and 12 participants did not provide their country of residence. Marriage lengths varied greatly, from seven months of marriage to 36.5 years of marriage, with five participants not indicating the length of their current marriage. The average marriage length in this sample was 11.7 years $(S D=93.27)$.

Table 1

Demographic statistics of study variables $(N=102)$

\begin{tabular}{lcc}
\hline Variable & $n$ & $\%$ \\
\hline Sex & & \\
$\quad$ Female & 96 & 94.1 \\
Male & 6 & 5.9 \\
Age & 2 & 2 \\
18-24 years & 37 & 36.3 \\
25-34 years & 40 & 39.2 \\
35-44 years & 20 & 19.6 \\
45-54 years & 3 & 2.9 \\
55-64 years & 9 & 8.9 \\
Ethnicity* & 92 & 91.1 \\
Hispanic or Latino & & \\
$\quad$ Not Hispanic or Latino & 4 & 4 \\
Race* & & \\
$\quad$ Asian or Asian American & &
\end{tabular}


Table 1 (Continued)

\begin{tabular}{|c|c|c|}
\hline Black or African American & 1 & 1 \\
\hline White & 94 & 94.9 \\
\hline \multicolumn{3}{|l|}{ Education Level } \\
\hline Less than $12^{\text {th }}$ Grade & 3 & 2.9 \\
\hline High School Diploma & 4 & 3.9 \\
\hline $\begin{array}{l}\text { Some college/university or } \\
\text { technical school, no } \\
\text { degree }\end{array}$ & 20 & 19.6 \\
\hline Associate's degree & 11 & 10.8 \\
\hline Bachelor's degree & 41 & 40.2 \\
\hline Master's degree & 17 & 16.7 \\
\hline $\begin{array}{l}\text { Professional degree } \\
\text { beyond a Bachelor's } \\
\text { degree/Doctorate (for } \\
\text { example: MD, DDS, } \\
\text { PhD, JD, LLB, DVM) }\end{array}$ & 6 & 5.9 \\
\hline \multicolumn{3}{|l|}{ Yearly income level* } \\
\hline$\$ 20,000-\$ 40,000$ & 13 & 13.1 \\
\hline$\$ 40,000-\$ 60,000$ & 13 & 13.1 \\
\hline$\$ 60,000-\$ 80,000$ & 24 & 24.2 \\
\hline$\$ 80,000-\$ 100,000$ & 14 & 14.1 \\
\hline$\$ 100,000-\$ 150,000$ & 25 & 25.3 \\
\hline Over $\$ 150,000$ & 10 & 10.1 \\
\hline
\end{tabular}

*Note: 3 participants did not indicate their income level, 3 participants did not indicate their race, and 1 participant did not indicate their ethnicity.

\section{Marital Satisfaction}

Results from the MAT were analyzed to determine marital satisfaction. Question 13 from the MAT was removed due to heteronormative scoring that was unable to be completed in the survey's current form (See Appendix C). With the question removed, the reliability of the MAT was acceptable $(\alpha=.65)$ (Jiang et al., 2013). The MAT was completed by 97 participants, with possible scores ranging from 2 to 148, with higher scores indicating higher levels of marital satisfaction. The lowest score received was 41 and the highest score received was 146 . The mean score was 107.68 with a standard deviation of 20.27 and the most commonly received score was 109 (5.2\%). Five 
participants did not answer any questions pertaining to the MAT and two participants did not complete the first question (a Likert scale which prompted participants to select how happy they felt in their present marriage).

\section{Perceived Spousal Support in Parenting}

The amount of perceived parental support in parenting was measured by the PAI. The measure was found to be reliable $(\alpha=.95)$. The PAI was attempted by 86 participants, with possible scores ranging from 20 to 100, with higher scores indicating higher levels of perceived spousal support in parenting. One participant completed only four questions, resulting in a score of 16. Omitting this outlier, scores between 42 and 100 were calculated for the remaining 85 participants. The mean score was 85.02 with a standard deviation of 13.2 and the score most often reported was 97 (7.1\%). All 86 participants answered the first questions of the PAI, however one question (my child's other parent is willing to make personal sacrifices to help take care of our child) had two responses missing, one question (my child's other parent makes my job of being a parent easier) had three responses missing, and each of the remaining questions had 1 response missing.

\section{Perceived Job Flexibility}

Levels of perceived job flexibility were calculated using Rothausen's (1994) measure of job flexibility. The measure was shown to be reliable $(\alpha=.88)$. For participants who reported being employed and having an employed spouse, scores for the participant and the spouse were averaged together to create one score. This measure was completed by 100 participants, with possible scores ranging from 5 to 25 , with higher scores indicating higher levels of perceived job flexibility. Actual scores were found to be 
between 6 and 25. The mean score was 19.7 with a standard deviation of 4.79 and the score of 25 seen most often. These scores were interpreted in a dichotomous manner, where scores of 15 and lower were considered to represent participants who were dissatisfied with job flexibility and scores above 15 were considered to represent participants who were satisfied with job flexibility. Missing responses only occurred for one question of this measure when the participant was asked to rate their own workplace (satisfaction with the ease of getting time off for family as needed), where 2 participants opted not to submit a response. When responding to this measure as it related to the participants' perception of their spouse's workplace, one participant failed to answer any of the five questions, and a second participant skipped two of the questions (satisfaction with the opportunity to do part-time or flex-time work without being penalized and satisfaction with the amount of flexibility in work scheduling).

\section{Correlations}

Using a dichotomous scoring method for "satisfied with job flexibility" or "dissatisfied with job flexibility," perceived job flexibility was positively correlated with scores from the PAI $(r=.335, \mathrm{p}<.05)$. However, scores from the job flexibility satisfaction were not correlated to the MAT. The PAI was positively correlated with the MAT $(r=.463, \mathrm{p}<.01)$. The age of the participant was correlated to job flexibility $(r=$ $.208, \mathrm{p}<.05)$ and to race $(r=.221, \mathrm{p}<.05)$. Average yearly income was positively correlated to job flexibility $(r=.286, \mathrm{p}<.01)$, age $(r=.240, \mathrm{p}<.05)$, and education levels $(r=.353, \mathrm{p}<.01)$. Significant correlations were not seen between the descriptive variables and the designed measures. Additional correlation results can be found in Table 2. 
Table 2

Correlations among study variables $(N=102)$

\begin{tabular}{|c|c|c|c|c|c|c|c|c|c|}
\hline Variables & 1 & 2 & 3 & 4 & 5 & 6 & 7 & 8 & 9 \\
\hline $\begin{array}{l}\text { 1. Job } \\
\text { Flexibility }\end{array}$ & --- & & & & & & & & \\
\hline $\begin{array}{l}\text { 2. Parenting } \\
\text { Alliance } \\
\text { Inventory }\end{array}$ & $.335^{*}$ & --- & & & & & & & \\
\hline $\begin{array}{l}\text { 3. Marital } \\
\text { Adjustment } \\
\text { Test }\end{array}$ & .145 & $.463 * *$ & --- & & & & & & \\
\hline 4. Age & $.208^{*}$ & -.147 & -.166 & --- & & & & & \\
\hline 5. Female & .121 & -.034 & .006 & .043 & --- & & & & \\
\hline 6. Ethnicity & .026 & -.142 & -.087 & .186 & -.089 & --- & & & \\
\hline 7. Race & -.015 & -.040 & -.126 & $.221^{*}$ & -.168 & -.059 & --- & & \\
\hline $\begin{array}{l}\text { 8. Education } \\
\text { Level }\end{array}$ & -.026 & -.012 & -.038 & -.006 & -.159 & .015 & -.107 & --- & \\
\hline $\begin{array}{l}\text { 9. Yearly } \\
\text { Income }\end{array}$ & $.286^{* *}$ & .119 & .009 & $.240^{*}$ & -.036 & .090 & .121 & $.353^{* *}$ & --- \\
\hline
\end{tabular}

Multiple Regression

Multiple regression was utilized to calculate martial satisfaction based on perceived job flexibility and perceived spousal support in parenting. The multiple regression model with the three variables found $R^{2}=.218, \mathrm{~F}(2,81)=11.295, \mathrm{p}<.000$. As can be seen in Table 3, perceived spousal support in parenting had positive regression weights, where participants' marital satisfaction increased .746 points for each unit 
increase in spousal support in parenting and was a significant predictor of marital satisfaction. Perceived job flexibility, however, was not seen to be a predictor of marital satisfaction. When controlling for demographics, perceived parental support in parenting was still significant, with marital satisfaction increasing .703 points for each unit increase in spousal support in parenting, and perceived job flexibility remained non-significant.

Table 3

Regression analysis results for study variables

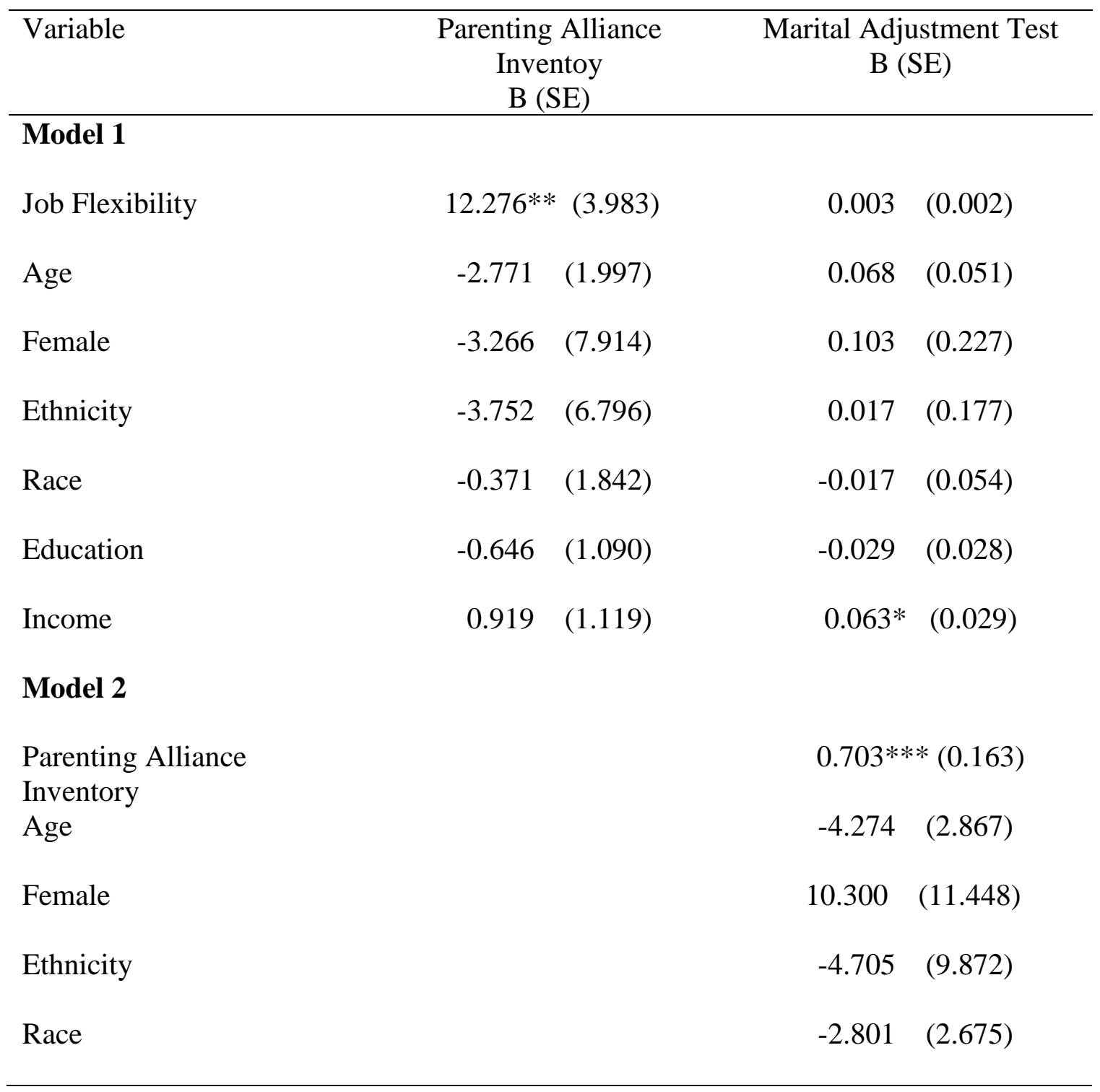


Table 3 (Continued)

\begin{tabular}{lcc}
\hline Education & -0.427 & $(1.585)$ \\
Income & 0.173 & $(1.593)$ \\
\hline Note: ${ }^{p}<.05, * * \mathrm{p}<.01, * * * \mathrm{p}<.001$ & &
\end{tabular}

\section{Mediation Model}

The mediation model required four steps in order to complete the analysis. In the first step, the causal variable (perceived job flexibility) must be correlated with the outcome variable (marital satisfaction) in order to move forward. During analysis, the variable of perceived job flexibility did not correlate to the variable of marital satisfaction, despite recoding job flexibility as reported above. Due to this failure to meet the requirements of the first step, the mediation model was unable to be completed as designed. In the absence of a mediating relationship, results indicated that perceived job flexibility was significantly associated with perceived spousal support in parenting $(r=$ $.335, \mathrm{p}<.05)$, and perceived spousal support in parenting was significantly correlated to marital satisfaction $(r=.463, \mathrm{p}<.01)$. This indicates a more linear path of influence between the variables, instead of a mediation model.

\section{Discussion}

The purpose of this study was to examine the impact of perceived job flexibility and perceived spousal support in parenting on the marital satisfaction of parents of children with special needs. The proposed mediation model was not supported by the data, however the results indicated a significant linear relationship between perceived job flexibility and perceived spousal support in parenting. Additionally, the results also 
indicated that perceived spousal support in parenting significantly increased marital satisfaction for parents of children with special needs.

The first hypothesis (H1) predicted that perceived job flexibility and martial satisfaction would be positively correlated. The data analyses, however, showed that there was no significant relationship between these two variables within this study, and this hypothesis was rejected. The absence of a relationship between these variables was contradictory to the findings from past studies. A 2001 study by Hill et al., found that individuals with more perceived job flexibility reported higher family and life satisfaction. Additionally, several past studies report that lower levels of job flexibility indicate lower levels of marital satisfaction (Hill et al., 2001; Henly et al., 2006; McNall et al., 2009; Shree, 2012; Yucel, 2017).

A potential explanation for this differing result is that job flexibility of souse was relayed by the participant, and not the spouse themselves. There is the possibility of discrepancy between these two points of view, especially as only one point of view was obtained. As has been seen in previous literature, the reporting of one spouse's perception by the other spouse is not always accurate (Elwood \& Jacobson, 1982; McCrae, Stone, Fagan, \& Costa, Jr., 1998; Priem, Solomon, \& Steuber, 2009). Asking both members of the couple to rate their own perceptions of their job flexibility and their perceptions of their spouse's job flexibility may have given a more accurate view. Another explanation may be that martial satisfaction questionnaires may not always be reliable, as the person completing the survey may distort their responses in order to reach some level of social desirability, instead of answering bluntly (Snyder, 1979). 
This study also predicted that the levels of perceived spousal support in parenting would have a positive correlation with marital satisfaction levels (H2). As predicted, participants with higher ratings of perceived spousal support in parenting responsibilities also had higher reported levels of marital satisfaction. This result was in agreeance with several other studies related to marital satisfaction and perceived spousal support in parenting (Bristol et al., 1988; Belsky et al., 1996; Wieland \& Baker, 2010; Holland \& McElwain, 2013), as well as the principles of the microsystem of the bioecological model, which suggested that the amount of time an individual has at home to provide parenting support can impact how much support their spouse feels in the parenting duties (Bronfenbrenner, 1994).

Feeling supported can indicate high levels of marital satisfaction (Wieland \& Baker, 2010), while high marital satisfaction can indicate greater quality parenting that is given to a child (Bristol et al., 1988). In the same vein, parents who feel that their spouse provides great care to their child tend to feel more satisfaction in their marital relationship (Belsky et al, 1996; Holland \& McElwain, 2013). This finding was similar to that of Holland \& McElwain (2013), who found that people who struggle in their roles as parents to children with special needs can carry that stress into their marital relationship. This finding has been similarly found in studies on parents with children with and without special needs (Bristol et al., 1998; Wieland \& Baker, 2010), which suggests that this result is more universal to parents in general, independent of any diagnoses or special need that their children may have.

A third hypothesis (H3) predicted that participants with higher perceived job flexibility would also report higher amounts of perceived spousal support in parenting. 
This hypothesis was supported in the research, as a positive correlation between these two variables was observed. This finding was also in agreeance with the principle of the exosystem within the bioecological model, which suggested that the workplace flexibility of a parent can impact the amount of time they have at home to care for their child with special needs (Bronfenbrenner, 1994). One explanation for this is that individuals with higher job flexibility simply have more time available in their schedules to spend interacting with their children with special needs and helping their spouse in the parenting role.

With higher levels of job flexibility, parents are more able to take turns caring for the children so the other partner can work, which increases feelings of being supported in parenting (Press \& Fagan, 2006). Additionally, previous research has also found that when work schedules can be adjusted around the needs of the family, individuals will experience less work-life conflict and have more opportunities to spend time with their children (Henly et al., 2006; McNall et al., 2009). This time may be necessary in order to provide children with special needs with necessary services, as in this study $75.3 \%$ of children attended between one and 12 hours of therapy appointments a month and $52.5 \%$ of children attended between one and 11 hours of medical appointments a month. Given these results, and the time required to spend caring for a child with special needs, it follows that having more flexibility in work schedules would increase the amount of time a parent would be able to dedicate to seeking care for their child and the amount of support their spouse feels in the shared parenting role.

The final hypothesis (H4) supposed that the relationship between perceived job flexibility and marital satisfaction would be mediated by perceived spousal support in 
parenting. Contrary to the prediction, perceived spousal support in parenting did not play a role in the relationship between perceived job flexibility and marital satisfaction. In congruence with previous works, perceived spousal support in parenting was positively correlated with marital satisfaction (Bristol et al., 1998; Wieland \& Baker, 2010). However, while past studies have found that lower amounts of job flexibility were related to lower amounts of marital satisfaction (Henly et al., 2006; McNall et al., 2009), this was not the case in the current research.

One explanation for the mediation model being unsupported is this variance in findings among previous work and the current study. The major variation seen between the past literature and the current study is that many previous studies have found that lower job flexibility is correlated with lower marital satisfaction (Hill et al., 2001; Henly et al., 2006; McNall et al., 2009; Shree, 2012; Yucel, 2017), where there was no relationship seen in this study. As with the first hypothesis (H1), this mediation may not have been found due to the participant reporting on the job flexibility of a spouse, instead of the spouse reporting their own feelings about their job flexibility. Additionally, these variables may have not been related in the predicted way due to two of the variables being informed by the participant's perception of their own experiences (marital satisfaction and perceived spousal support in parenting), and one of the variables being informed by the participant's perception of their spouse's experience (spouse's perceived job flexibility). It is also worth noting that while spousal support in parenting practices and the schedule flexibility of workplaces have been acknowledged in studies concerning job, life, and marital satisfaction of individuals (Belsky et al., 1996; Bristol et al., 1988; Hill et al., 2001; Michel \& Michel, 2015; Vandello et al., 2013; Wieland \& Baker, 2010), 
there is a deficit in existing studies on the interconnection of these factors with which to compare the results of this study.

Although the mediation model was not supported by the results, there were other valuable findings. Most notably, a connection between the three main variables was found after adjusting the parameters of perceived job flexibility. Instead of the predicted mediation model, a model of influence that suggested more of a straight pathway of linkage between the variables was found. The results showed that higher amounts of job flexibility indicated higher amounts of perceived spousal support in parenting, which then indicated higher amounts of martial satisfaction (See Figure 2). This finding is supported by previous research, as an individual with more time available (higher job flexibility) to spend at home assisting their spouse in the parenting role (perceived spousal support in parenting) is likely to experience more satisfaction in their personal relationship with their spouse (marital satisfaction) (Brown \& Booth, 2002; Henly et al., 2006; McNall et al., 2009). This model is strictly an interpretation of the results found in this particular study. Each segment of this model was seen in the results of this study, however the model as a whole has not yet been tested and will require future studies to determine any validity. 


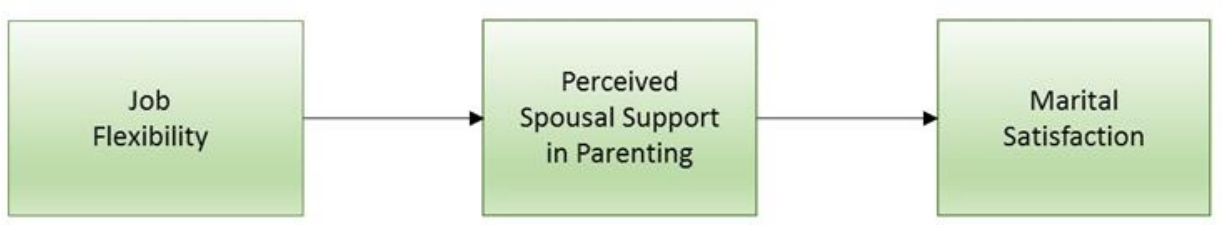

Figure 2. Interpreted model of the relationship between job flexibility, perceived spousal support in parenting, and marital satisfaction based on the data analysis.

In addition to the findings related to the specific hypotheses, there were other results worth noting. For instance, there was a correlation between income level and perceived job flexibility, where level of yearly income was higher when perceived job flexibility was higher. This finding was also seen in related studies (Gerstel \& Clawson, 2014; Williams, 2010), indicating that individuals in higher paid occupations may have greater workplace benefits, such as flexibility in scheduling. Another interesting finding was that $58 \%$ of the children reported upon in this study held a diagnosis of Down syndrome. This majority reporting could have influenced the measured variables, as previous works have suggested that parenting a child with Down syndrome may cause less stress than parenting a child with a differing special needs diagnosis (Kasari \& Sigman, 1997; Fidler, Hodapp, \& Dykens, 2000; Hodapp et al., 2001). Additionally, there is a more pronounced difference in divorce rates for parents of children with ADHD and ASD (Hartley et al., 2010; Pickar \& Kaufman, 2015; Wymbs et al., 2008), suggesting 
that examining the diagnosis of a child may be of value in finding trends. With more diversity in diagnoses of the sample, the outcomes of the measures of perceived spousal support in parenting and marital satisfaction may have varied.

\section{Strengths and Limitations}

The major strength of this survey was the measures utilized within the survey instrument. This survey used the PAI to measure spousal support in parenting, which has been shown to have a high reliability (.97) in previous measures (Abidin \& Brunner, 1995), as well as in the current study (.95). The measure used to rate job flexibility has seen high reliability (.87) in previous work (Rothausen, 1994), and was also see to be reliable in the current research (.88). Additionally, the third measure utilized by this survey, the MAT, was used to measure marital satisfaction and has shown high reliability (.90) in the past (Ato et al., 2015; Saxbe et al., 2008), and had an acceptable reliability (.65) rating within this study (Jiang et al., 2013). Another strength of this study was that the use of the internet allowed for gathering participants from many different locations within the United States (31 different states) and a few participants from outside of the United States (3.3\% from Canada and 1.1\% from the United Kingdom of Great Britain and Northern Ireland). This is valuable because work standards may vary from region to region, so having a collection of areas to report on allows for a broader overall interpretation of the results.

While this study had strengths which promoted its value and contribution to the field, there were also limitations in the research. One of the clearest limitations of this study was the amount of participants who did not fully complete the questionnaire. Where 128 participants attempted the survey, not all participants were able to submit 
surveys with every section completed. Related to this issue is that of the length and duration of the survey. The survey had 75 questions if the participant and their spouse were both employed and had one child with special needs and it was estimated to take 25 minutes to complete. The survey may have been better received and achieved higher rates of completion if both the duration of the survey and the number of questions were less. Additionally, this survey was advertised and offered online, which may have contributed to the lack of diversity in the participant sample, as the majority of participants were female $(94.1 \%)$ and identified as white $(92.2 \%)$. This study did not offer any incentives for participating and a major theme of this survey was related to health and wellness; which are both factors that predict a higher rate of female responses than male responses (Eysenbach \& Wyatt, 2002). A final limitation to consider is that of the distribution of the actual survey. This study utilized snowball sampling methods and relied heavily on individuals using their social media accounts to share the survey with others. It is possible that some individuals did not feel comfortable posting an advertisement for this research or that those who did share the advertisement had a limited social media presence, which could have contributed to low numbers of participation.

\section{Implications for Future Research}

This research examined the factors that influence the marital satisfaction of parents of children with special needs. Studies on this topic are necessary in order to support and represent families of all designs in research and in practice. Future work is encouraged to utilize the strengths of this research, as well as, work towards eliminating the limitations seen in this study. Studies should seek measures that have high reliability, as seen in the measures of the Parenting Alliance Inventory (PAI), the Marital 
Adjustment Test (MAT), and Rothausen's (1994) measure of job flexibility in this

research. Additionally, future studies should build upon the limitations found in this study in order to obtain more accurate and more representative results. Designing studies which illicit more male participants, such as offering incentives for completing an online survey (Eysenbach \& Wyatt, 2002), will help to broaden the sample. Also, when studying marital satisfaction, having the input of both members of the relationship may give greater insight into the health and happiness of a marriage. This may be especially worth dedicating more resources into researching for the parents of children with special needs, as each parent may carry the weight of parenting responsibilities and expectations differently (Press \& Fagan, 2006). Future research should also consider collecting diagnosis specific data, as the stress of parenting responsibilities may differ based upon the severity of the child's diagnosis (Hartley et al., 2010; Pickar \& Kaufman, 2015; Wymbs et al., 2008). In regards to job flexibility, examining the specific occupational fields of the participants in more detail in future works may show insight into career paths that are more flexible for families, and career fields that need to develop more family friendly guidelines for employees.

\section{Implications for Practice}

Understanding the variables that influence a couple's perception of the marital satisfaction is valuable to family professionals. In order to promote healthy, happy families, it is necessary to be able to confront any areas that may make these personal relationships more difficult to maintain. In the instance of divorce, children with special needs and their parents may both experience detriments to psychological health and standards of living (Jekielek, 1998; Morrison \& Coiro, 1999; Forste \& Heaton, 2004; 
Peris et al., 2008), therefore continuing to promote healthy relationships is of benefit to families. In preventing divorce, marriage and family therapists should examine the amount of parenting support an individual feels from their spouse in caring for their child with special needs, as this can impact the marriage quality. These family professionals should encourage their clients to find common ground and compromise in parenting roles (Press \& Fagan, 2006), in addition to any activities prescribed for improving the marital relationship itself.

Given that this study found connections between perceived job flexibility and perceived spousal support in parenting, it will be beneficial to consider the implications for workplace policy. In order for parents to fulfill their family obligations, allowing more freedom in the work schedule can grant parents more opportunities to take care of their children and ensure that they attend necessary appointments. Children with special needs often require more medical appointments than children without special needs (Daire et al., 2011), increasing the need to ensure that all working parents are able to balance work responsibilities with family obligations. This ability to contribute more to the parenting role should then also positively impact the parents' levels of marital satisfaction in their personal relationship, as seen in previous works (Ato et al., 2015).

\section{Conclusion}

This study met its purpose of examining the factors of perceived job flexibility and spousal support in parenting and how they influence the marital satisfaction of parents of children with special needs. While not all of the initial predictions were met, important links between the variables were supported, which can be examined more intimately in future studies. The major findings, that perceived job flexibility was 
positively correlated with perceived spousal support in parenting, and perceived spousal support in parenting was positively correlated with marital satisfaction, were supported by the bioecological model and previous research in this field. The unique dynamics of families with children with special needs were considered and the benefits of a healthy, happy marriage for both the parents and the children within the family were promoted. In order to support these values, family researchers must continue to examine the factors that influence the quality of life for the underserved population of families with children with special needs, and for all families in general. 


\section{APPENDIX A - Survey Instrument}

\section{Demographic Information}

1. What is your age?
a. 18 to 24 years
b. 25 to 34 years
c. 35 to 44 years
d. 45 to 54 years
e. 55 to 64 years
f. Age 65 or older

2. In what country do you currently reside?

-This will be a dropdown box with options

-If answer is United States, then

2a. Which state do you live in?

-This will be a dropdown box with options

3. What is your sex?
a. Female
b. Male
c. Other

4. What is your ethnicity?
a. Hispanic or Latino
b. Not Hispanic or Latino

5. What is your race?

a. Asian or Asian American 

b. Black or African American
c. Native Hawaiian or Other Pacific Islander
d. Native American or Alaska Native
e. White

6. Please select the highest level of education you have completed:
a. Less than $12^{\text {th }}$ grade
b. High School diploma
c. GED or alternative credential
d. Some college/university or technical school, no degree
e. Associate's degree
f. Bachelor's degree
g. Master's degree
h. Professional degree beyond a bachelor's degree/ Doctorate (for example: MD, DDS, PhD, JD, LLB, DVM)

7. Please select your household's yearly income:
a. $\$ 20,000-\$ 40,000$
b. $\$ 40,000-\$ 60,000$
c. $\$ 60,000-\$ 80,000$
d. $\$ 80,000-\$ 100,000$
e. $\$ 100,000-\$ 150,000$
f. Over $\$ 150,000$ 


\section{Employment}

Please answer the following questions related to employment.

8. Are you currently employed?

a. Yes

b. No

-If No, participants will skip to question 9.

-If Yes, the following will be asked:

8a. Please indicate what your current occupation is:

8b. Approximately how many hours a week do you work:

$8 \mathrm{c}$.

\begin{tabular}{|l|l|l|l|l|l|}
\hline & Always & $\begin{array}{l}\text { Almost } \\
\text { Always }\end{array}$ & Occasionally & $\begin{array}{l}\text { Almost } \\
\text { Never }\end{array}$ & Never \\
\hline $\begin{array}{l}\text { How often do you } \\
\text { feel that your } \\
\text { employer is flexible } \\
\text { in allowing you time } \\
\text { off to address family } \\
\text { needs? }\end{array}$ & & & & & \\
\hline
\end{tabular}

$8 \mathrm{~d}-8 \mathrm{~h}$. Please answer the following questions about your current workplace.

\begin{tabular}{|l|l|l|l|l|l|}
\hline & $\begin{array}{l}\text { Strongly } \\
\text { dissatisfied }\end{array}$ & $\begin{array}{l}2 \\
\text { Somewhat } \\
\text { dissatisfied }\end{array}$ & $\begin{array}{l}3 \\
\text { Neither } \\
\text { dissatisfied } \\
\text { nor } \\
\text { satisfied }\end{array}$ & $\begin{array}{l}4 \\
\text { Somewhat } \\
\text { satisfied }\end{array}$ & $\begin{array}{l}\text { Strongly } \\
\text { Satisfied }\end{array}$ \\
\hline $\begin{array}{l}\text { 8d. The extent to } \\
\text { which management } \\
\text { accommodates family } \\
\text { responsibility needs } \\
\text { without any negative } \\
\text { consequences }\end{array}$ & & & & & \\
\hline
\end{tabular}




\begin{tabular}{|l|l|l|l|l|l|}
\hline $\begin{array}{l}\text { 8e. The opportunity to } \\
\text { perform your job well } \\
\text { and yet be able to } \\
\text { perform home-related } \\
\text { duties adequately }\end{array}$ & & & & & \\
\hline $\begin{array}{l}\text { 8f. The ease of getting } \\
\text { time off for family as } \\
\text { needed }\end{array}$ & & & & & \\
\hline $\begin{array}{l}\text { 8g. The opportunity to } \\
\text { do part-time or flex- } \\
\text { time work without }\end{array}$ & & & & & \\
being penalized & & & & & \\
\hline $\begin{array}{l}\text { 8h. The amount of } \\
\text { flexibility in work }\end{array}$ & & & & & \\
scheduling & & & & \\
\hline
\end{tabular}

9. Is your spouse currently employed?
a. Yes
b. No

-If $N o$, participants will skip to question 10.

-If Yes, the following will be asked:

9a. Please indicate what your spouse's current occupation is:

9b. Approximately how many hours a week does your spouse work

9c.

\begin{tabular}{|l|l|l|l|l|l|}
\hline & Always & $\begin{array}{l}\text { Almost } \\
\text { Always }\end{array}$ & Occasionally & $\begin{array}{l}\text { Almost } \\
\text { Never }\end{array}$ & Never \\
\hline $\begin{array}{l}\text { How often do you feel } \\
\text { that your spouse's } \\
\text { employer is flexible in } \\
\text { allowing your spouse } \\
\text { time off to address } \\
\text { family needs? }\end{array}$ & & & & & \\
\hline
\end{tabular}


$9 \mathrm{~d}-9 \mathrm{~h}$. Please answer the following questions about your spouse's current workplace.

\begin{tabular}{|l|l|l|l|l|l|}
\hline & $\begin{array}{l}1 \\
\text { Strongly } \\
\text { dissatisfied }\end{array}$ & $\begin{array}{l}2 \\
\text { Somewhat } \\
\text { dissatisfied }\end{array}$ & $\begin{array}{l}3 \\
\text { Neither } \\
\text { dissatisfied } \\
\text { nor } \\
\text { satisfied }\end{array}$ & $\begin{array}{l}4 \\
\text { Somewhat } \\
\text { satisfied }\end{array}$ & $\begin{array}{l}\text { Strongly } \\
\text { Satisfied }\end{array}$ \\
\hline $\begin{array}{l}\text { 9d. The extent to } \\
\text { which management } \\
\text { accommodates family } \\
\text { responsibility needs } \\
\text { without any negative } \\
\text { consequences }\end{array}$ & & & & & \\
\hline $\begin{array}{l}\text { 9e. The opportunity to } \\
\text { perform the job well } \\
\text { and yet be able to } \\
\text { perform home-related } \\
\text { duties adequately }\end{array}$ & & & & & \\
\hline $\begin{array}{l}\text { 9f. The ease of getting } \\
\text { time off for family as } \\
\text { needed }\end{array}$ & & & & & \\
\hline $\begin{array}{l}\text { 9g. The opportunity to } \\
\text { do part-time or flex- } \\
\text { time work without } \\
\text { being penalized }\end{array}$ & & & & & \\
\hline $\begin{array}{l}\text { 9h. The amount of } \\
\text { flexibility in work } \\
\text { scheduling }\end{array}$ & & & & & \\
\hline
\end{tabular}

\section{Marriage}

Please consider your current marriage when answering the questions.

10. Please enter the duration of your current marriage in years and months: Years ___ Months

11. Select the dot on the scale line below which best describes the degree of happiness, everything considered, of your present marriage. The middle point, "happy," represents the degree of happiness which most people get from marriage, and the scale gradually 
ranges on one side to those few who are very unhappy in marriage, and on the other, to those few who experience extreme joy in marriage.

Very Unhappy Happy Herfectly Happy

12. For each of the following, please select whether you and your mate "always agree," "almost always agree," "occasionally disagree," "frequently disagree,"

"almost always disagree," or "always disagree," on the topics listed.

\begin{tabular}{|c|c|c|c|c|c|c|}
\hline & $\begin{array}{l}\text { Always } \\
\text { Agree }\end{array}$ & $\begin{array}{l}\text { Almost } \\
\text { Always } \\
\text { Agree }\end{array}$ & $\begin{array}{l}\text { Occasionally } \\
\text { Disagree }\end{array}$ & $\begin{array}{l}\text { Frequently } \\
\text { Disagree }\end{array}$ & $\begin{array}{l}\text { Almost } \\
\text { Always } \\
\text { Disagree } \\
\end{array}$ & $\begin{array}{l}\text { Always } \\
\text { Disagree }\end{array}$ \\
\hline $\begin{array}{l}\text { 12a. Handling } \\
\text { family finances }\end{array}$ & & & & & & \\
\hline $\begin{array}{l}\text { 12b. Matters of } \\
\text { recreation }\end{array}$ & & & & & & \\
\hline $\begin{array}{l}12 \mathrm{c} . \\
\text { Demonstration } \\
\text { of affection }\end{array}$ & & & & & & \\
\hline 12d. Friends & & & & & & \\
\hline $\begin{array}{l}\text { 12e. Sex } \\
\text { relations }\end{array}$ & & & & & & \\
\hline $\begin{array}{l}12 \mathrm{f} . \\
\text { Conventionality } \\
\text { (right, good, or } \\
\text { proper conduct) }\end{array}$ & & & & & & \\
\hline
\end{tabular}




\begin{tabular}{|l|l|l|l|l|l|l|}
\hline $\begin{array}{l}\text { 12g. Philosophy } \\
\text { of life }\end{array}$ & & & & & & \\
\hline $\begin{array}{l}\text { 12h. Ways of } \\
\text { dealing with in- } \\
\text { laws }\end{array}$ & & & & & & \\
\hline
\end{tabular}

13. When disagreements arise, they usually result in:
a. Mate giving in
b. Me giving in
c. Agreement by mutual give and take

14. Do you and your mate engage in outside interests together?
a. All of them
b. Some of them
c. Very few of them
d. None of them

15. In leisure time do you generally prefer:
a. to be "on the go"
b. to stay at home

16. Does your mate generally prefer:
a. to be "on the go"
b. to stay at home

17. Do you ever wish you had not married?

a. Frequently 

b. Occasionally
c. Rarely
d. Never

18. If you had your life to live over, do you think you would:
a. Marry the same person
b. Marry a different person
c. Not marry at all

19. Do you confide in your mate:
a. Almost never
b. Rarely
c. In most things
d. In everything

\section{Children}

Please answer the following questions as they pertain to your child/children.

20. How many children are dependents in your home?

21. How many of your children have a special needs diagnosis?

Please answer the following questions as they pertain to your child with a special needs diagnosis. If you have more than one child with special needs, please consider only one of your children when responding to the following questions. You will be able to answer the questions for any additional children after completing these.

\section{Child 1:}

22. Please indicate how old your child with special needs is in years and months: 
Years Months

23. Please indicate your child's primary diagnosis:

24. Approximately how many medical appointments has your child attended in the last month?

Medical Appointments

25. Approximately how many therapy appointments has your child attended in the last month?

Therapy Appointments

26. Approximately how many hours of medical appointments has your child attended in the last month?

Hours of Medical Appointments

27. Approximately how many hours of therapy appointments has your child attended in the last month?

Hours of Therapy Appointments

28. Which of the following is the most accurate?
a. I take my child to all of their appointments
b. I take my child to most of their appointments
c. I take my child to a few of their appointments
d. I do not take my child to their appointments

29. Which of the following is the most accurate?

e. My spouse takes our child to all of their appointments 
f. My spouse takes our child to most of their appointments

g. My spouse takes our child to a few of their appointments

h. My spouse does not take our child to their appointments

30. Do you have an additional child with special needs to enter information for?
a. Yes
b. No

-If Yes, questions 22 through 30 are repeated until the participant answers No. Headings will change to say Child 2, Child 3, etc. until participant answers No.

31. Please consider you child/children with special needs when answering the following questions.

\begin{tabular}{|l|l|l|l|l|l|}
\hline $\begin{array}{l}\text { 31a. My child's other parent } \\
\text { enjoys being alone with our } \\
\text { child }\end{array}$ & $\begin{array}{l}\text { Strongly } \\
\text { Agree }\end{array}$ & Agree & $\begin{array}{l}\text { Not } \\
\text { Sure }\end{array}$ & Disagree & $\begin{array}{l}\text { Strongly } \\
\text { Disagree }\end{array}$ \\
\hline $\begin{array}{l}\text { 31b. During pregnancy, my } \\
\text { child's other parent } \\
\text { expressed confidence in my } \\
\text { ability to be a good parent }\end{array}$ & & & & \\
\hline $\begin{array}{l}\text { 31c. When there is a } \\
\text { problem with our child, we } \\
\text { work out a good solution } \\
\text { together }\end{array}$ & & & & & \\
\hline $\begin{array}{l}\text { 31d. My child's other parent } \\
\text { and I communicate well } \\
\text { about our child }\end{array}$ & & & & & \\
\hline $\begin{array}{l}\text { 31e. My child's other parent is } \\
\text { willing to make personal }\end{array}$ & & & & & \\
\hline
\end{tabular}




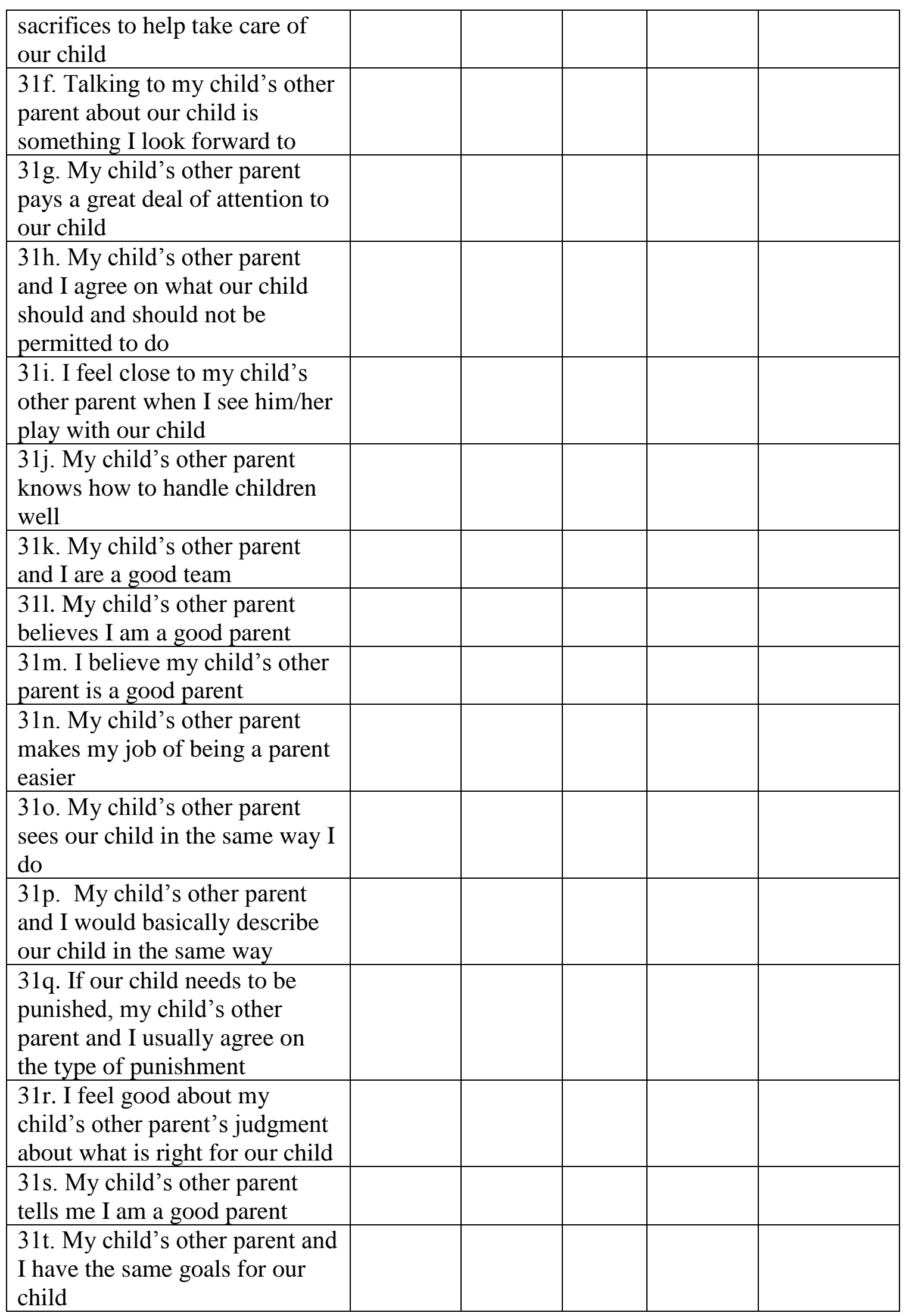


This concludes the questionnaire. Thank you for participating in this survey, your input is greatly valued!

If you are feeling any discomfort after completing this survey and would like access to mental health services, please utilize the National Hopeline Network at 1-800-784-2433 or visit www.therapistlocator.net to find a service provider near you.

If you would like more information on special needs diagnoses and interventions or parenting support, please utilize the Parent Helpline at 778.782 .3548 or visit http://www.parentcenterhub.org/repository/journey/ for additional resources. 


\section{APPENDIX B - IRB Approval Letter}

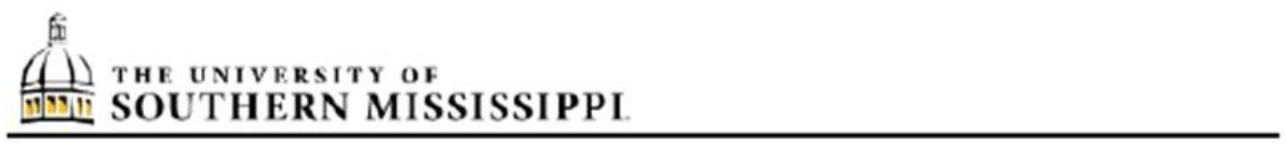

INSTITUTIONAL REVIEW BOARD

118 College Drive $\# 5147$ | Hattiesburg, MS 39406-0001

Phone: 601.266 .5997 |Fax: 601.266 .4377 | www.usmedu/research/institutional review.board

\section{NOTICE OF COMMITTEE ACTION}

The project has been reviewed by The University of Southern Mississippi Institutional Review Board in accordance with Federal Drug Administration regulations (21 CFR 26, 111), Department of Health and Human Services (45 CFR Part 46), and university guidelines to ensure adherence to the following criteria:

- The risks to subjects are minimized.

- The risks to subjects are reasonable in relation to the anticipated benefits.

- The selection of subjects is equitable.

- Informed consent is adequate and appropriately documented.

- Where appropriate, the research plan makes adequate provisions for monitoring the data collected to ensure the safety of the subjects.

- Where appropriate, there are adequate provisions to protect the privacy of subjects and to maintain the confidentiality of all data.

- Appropriate additional safeguards have been included to protect vulnerable subjects.

- Any unanticipated, serious, or continuing problems encountered regarding risks to subjects must be reported immediately, but not later than 10 days following the event. This should be reported to the IRB Office via the "Adverse Effect Report Form".

- If approved, the maximum period of approval is limited to twelve months. Projects that exceed this period must submit an application for renewal or continuation.

PROTOCOL NUMBER: 17022113

PROJECT TITLE: The Influence of Perceived Job Flexibility and Spousal Support on the Marital Satisfaction of Parents of Children with Special Needs

PROJECT TYPE: New Project

RESEARCHER(S): Katie Perlowski

COLLEGE/DIVISION: College of Education and Psychology

DEPARTMENT: Child and Family Studies

FUNDING AGENCYISPONSOR: N/A

IRB COMMITTEE ACTION: Exempt Review Approval

PERIOD OF APPROVAL: 03/14/2017 to 03/13/2018

Lawrence A. Hosman, Ph.D.

Institutional Review Board 


\section{APPENDIX C - Thesis Proposal}

\section{INTRODUCTION}

The marital satisfaction of parents who have children with special needs has been examined as a subject of interest by many family researchers (Daire, Munyon, Carlson, Kimemia, \& Mitcham, 2011; Kersh, Hedvat, Hauser-Cram, \& Warfield, 2006; Smith \& Grzywacz, 2014). As children with special needs tend to require more unique care than children without special needs, different dynamics may be observed among their families. Past research has focused on the interaction between the couple as it relates to their child's behavior (Kersh et al., 2006). While this is valuable to study, as children with behavioral issues do influence the rest of the family's functioning (Smith \& Grzywacz, 2014; Starr, 1981), there are other aspects that should be examined as well. With prevalence rates indicating that about $13 \%$ of children ages three to 17 years have a special needs diagnosis (National Center for Educational Statistics, 2016), there is a significant population of families who may benefit from research into marital satisfaction as it pertains to the parents of children with special needs.

Estimates suggest that nearly half of all marriages will end in divorce (Kazdin, 2000). While statistics on the occurrence of divorce within families of children with special needs may vary between sources (Barkley, Fischer, Edelbrock, \& Smallish, 1991; Minde et al., 2003; Wymbs et al., 2008), it has been estimated that as many as 70\% to $80 \%$ of marriages of parents of children with special needs will end in divorce (Sobsey, 2004). The detrimental effects that divorce can have on a child are well-documented in recent years (Fergusson et al., 2014; Weaver \& Schofield, 2015; Woody, 2009), as the access to and the acceptance of divorce have become more prominent. Divorce can 
impact the social, mental, and physical well-being of children regardless of whether or not they have a special needs diagnosis, however, for children with special needs, these effects may be experienced in more nuanced ways (Fergusson, McLeod, \& John Horwood, 2014; Weaver \& Schofield, 2015; Wymbs et al., 2008). For children whose daily functioning relies heavily on set schedules and routines, this change in family structure could disrupt many aspects of their developmental progress because while parents in today's society tend to overschedule their children in an attempt to cultivate additional skills (Hofferth \& Sandberg, 2001), many children with special needs require strict scheduling in order to promote their functional abilities and ensure that all of their medical needs are met (Weaver \& Schofield, 2015; Wymbs et al., 2008).

Studies have also found that single mothers experience more distress, depressive symptoms, and more negative life events on average than married mothers (Iobst et al., 2009). For children, the likelihood of poor school performance, behavioral problems, and psychological distress are increased when they transition from a two-parent to a singleparent household structure (Hoffman, 2006; Jablonska \& Lindberg, 2007; Iobst et al., 2009). These findings support the benefits or a two-parent household and highlight the necessity of identifying influencers of marital satisfaction to promote healthier and happier marriages and families in order to decrease the rates of divorce. Measures of marital satisfaction can provide insight into those at risk for divorce, as married individuals who report low levels of marital satisfaction are more likely to have their marriage end in divorce (Gottman, 2014; Karney \& Bradbury, 1997).

Traditional family roles are changing across the country within families of all designs. As dual-income households are growing increasingly more normative, the more 
traditional roles of the family must evolve as well (Hill, Hawkins, Ferris, \& Weitzman, 2001). When both parents in a family work outside of the home, balancing the responsibilities of an occupation and parenting roles becomes vital to functioning. Since children with special needs often attend more medical and therapy appointments than children without special needs, parents must be able to set aside time from their jobs and additional responsibilities to ensure that their children receive the services they require (Daire et al., 2011; Pickar \& Kaufman, 2015). For working parents, having a flexible job schedule may ease some of the worry or stress related to missing work in order to care for their children (Henly, Shaefer, \& Waxman, 2006; McNall, Masuda, \& Nicklin, 2009). In the instance that a parent has very low job flexibility, there may be times when they are unable to take their child to an appointment because of work demands and the fear of becoming unemployed (Allen, Johnson, Kiburz, \& Shockley, 2013). Even in singleincome households, having flexibility in the workplace may grant more freedom to take care of family needs and to support their spouse in caring for the children (Crettenden, Wright, \& Skinner, 2014).

With the additional time, money, and energy spent caring for a child with special needs, feeling supported by others is needed for the parents' mental and physical wellbeing. Parents who struggle with the responsibilities of their role as parent to a child with special needs can bring this stress into their intimate relationships and suffer from marital discord as well, which can lead to divorce (Holland \& McElwain, 2013). For marriages in general, being supported by a spouse is beneficial to both members of the couples' overall health (Priem, Solomon, \& Steuber, 2009). The perception that an individual has 
of how their spouse helps with parenting responsibilities may impact how connected they feel to their spouse in other aspects (Wieland \& Baker, 2010).

Previous research has not explored all of the potential factors influencing the marital satisfaction of parents of children with special needs. There is a tendency to focus on how a child's behavior impacts family functioning and marital intimacy. While this is important to examine, as studies have shown that when children with special needs display more extreme or aggressive behaviors their parents report less satisfaction in their marriage, this places a certain degree of responsibility onto the child that is unfavorable (Smith \& Grzywacz, 2014; Starr, 1981). It is necessary to understand that all members of the family can influence each other (Bowen, 1978), however it is also essential to scrutinize more complex areas of parents' daily lives that may impact their marital relationship, as opposed to only causal influences. Examining external factors, such as workplace flexibility, and internal factors, such as perceptions of the other parent's support, may provide a broader view into the various influences that both members of the couple bring into their intimate relationship. Using the bioecological model as its guide, this research will examine how family influence operates within the marital relationship.

The purpose of this study is to examine the factors that influence the marital satisfaction of parents of children with special needs. Previous studies have investigated this topic on the surface by doing comparisons of the marital satisfaction of parents with and without children with special needs (Daire et al., 2011; Starr, 1981). These previous studies have attempted to answer a broad question of how these relationships are informed by the presence of a child with special needs existing within the fabric of the family. There is more to consider when it comes to the well-being of these families, 
however, and this study aims to expand upon the areas that have been examine while also digging deeper into the intricacies that influence how couples balance their marital intimacy in addition to their responsibilities as parents of children with special needs. Specifically, this study will consider how the factors of perceived job flexibility and perceived spousal support in parenting may inform marital satisfaction.

This study contributes to the literature in several key ways. Initially, this study aims to investigate factors influencing the marital satisfaction of couples with children with special needs, which have not been given enough attention in previous work. By exploring perceived job flexibility and perceived spousal support, this work may find novel information that could be of benefit to future studies regarding marital satisfaction and the prevention of divorce. With the rates of divorce for parents of children with special needs within the United States resting around 70-80\% (Sobsey, 2004), this study could help to inform marriage counselors and therapists of additional dynamics within the relationship that may be worth addressing in sessions with their clients in order to improve the quality of the marital relationship. Also, by examining the influence of job flexibility, this study may contribute to public policy regarding workers' rights and improvement in working conditions to bolster the work-life balance of employees. Finally, any limitations found within this research may be built upon and influence the direction that studies of this nature follow in the future. 


\section{Definition of Key Terms}

This list was created in order to provide a clear and concise interpretation of the key terms and theories utilized in this study:

1. Special Needs: An umbrella term used to describe a population meeting the following definition:

“Any physical, developmental, mental, sensory, behavioral, cognitive, or emotional impairment or limiting condition that requires medical management, health care intervention, and/or use of specialized services or programs. The condition may be congenital, developmental, or acquired through disease, trauma, or environmental cause and may impose limitations in performing daily self-maintenance activities or substantial limitations in a major life activity. Health care for individuals with special needs requires specialized knowledge acquired by additional training, as well as increased awareness and attention, adaptation, and accommodative measures beyond what are considered routine" (Council on Clinical Affairs, 2012).

2. Marital Satisfaction: The general degree of happiness felt in a marriage in addition to the level of agreement or disagreement on critical issues faced by married persons (Priem et al., 2009). Measured in this study by using the Marital Adjustment Test (MAT).

3. Perceived Spousal Support in Parenting: The amount to which a person trusts in their partner's parenting capabilities and feels supported by their partner in 
the parenting process (Abidin \& Brunner, 1995; Holland \& McElwain, 2013).

Measured in this study by using the Parenting Alliance Inventory (PAI).

4. Job Flexibility: The degree to which a worker feels that they have flexibility in the scheduling of work hours and in balancing family and work responsibilities (Rothausen, 1994). Measured in this study by using Rothausen's (1994) measure of job flexibility.

5. Bioecological Model of Human Development: Bronfenbrenner's (1994) theory that explains that human development is influenced by the multiple levels of interactions, either direct or indirect, that they encounter in their daily lives. It suggests that varying systems of environments that the individual is connected with can affect their development (Bronfenbrenner, 1994).

\section{Research Questions}

The purpose of conducting this research is to examine factors that influence the marital satisfaction of parents of children with special needs diagnoses, specifically the influences of perceived spousal support in parenting and job flexibility. The following questions will guide the direction of this study:

- Will marital satisfaction be higher in couples where one or both parents of a child with special needs have perceived job flexibility?

- Does the amount of perceived spousal support in parenting responsibilities impact the level of marital satisfaction of parents of a child with special needs?

- Does the amount of job flexibility one partner has influence the amount of perceived parental support from a spouse? 
- Will perceived spousal support in parenting mediate the relationship between job flexibility and marital satisfaction for parents of children with special needs?

These research questions were used to inform the creation of a survey instrument intended to measure the abovementioned factors. The data will be analyzed using the technique of linear regression and will be presented in the form of a mediation model.

\section{LITERATURE REVIEW}

In the modern landscape of the United States society, there is a changing ideology about the institution of marriage. Daugherty and Copen (2016) found that increases in cohabitation, births outside of marriage, age at first marriage, and a decrease in fertility have contributed to changes in the normative family structure of the United States over the last 50 years. Other potential influencers, such as improvements towards gender equality, greater numbers of young people receiving higher education, and a weakened financial economy, may also be responsible for the evolution of ideas and traditions surrounding marriage (Fincham \& Beach, 2010). Additionally, the social acceptance of divorce, premarital intercourse, same-sex marriages, and cohabitation have significantly increased in recent times as the demographic structure of the US has also shifted (Copen, Daniels, \& Mosher, 2013; Daugherty \& Copen, 2016). There is even evidence to suggest the possibility of social networks having influence on which couples will divorce (McDermott, Fowler, \& Christakis, 2013).

Research has indicated that many people feel that when a couple cannot solve their marital issues, divorce may be the best option for resolution (Daugherty \& Copen, 2016). In fact, one in three adults agree that marriage has not worked for most of the 
people they know in their lives (Daugherty \& Copen, 2016). Regardless of common beliefs or current norms, the life events of both marriage and divorce can both be considered very common events among families in current society (Kazdin, 2000). A Center for Disease Control and Prevention (CDC) survey from 2014 reported that the rate of marriage for the year was 6.9 per 1,000 total population, with an estimate of 2,140,272 marriages country wide, and the American Psychological Association reported that over 90\% of individuals will marry before the age of 50 (Kazdin, 2000; National Center for Health Statistics, 2016). Alternatively, the CDC reports that the divorce rate is approximately 3.2 per 1,000 total population and the APA estimates that 40 to 50 percent of marriages will result in divorce, with rates for successive divorces being even greater (Kazdin, 2000; National Center for Health Statistics, 2016).

Divorce rates are significantly higher among parents of children with special needs (Sobsey, 2004; Wymbs et al., 2008). This difference is pronounced among parents of children with attention-deficit/hyperactivity disorder (ADHD) and autism spectrum disorder (ASD) compared to the general population (Hartley et al., 2010; Pickar \& Kaufman, 2015; Wymbs et al., 2008). Compared to parents of children without ADHD, parents of children with ADHD have been found to have more fights, utilize less positive and more negative statements when discussing parenting, and report lower levels of satisfaction in marriage (Wymbs et al., 2008). 


\section{Bioecological Systems Model}

Bronfenbrenner's (1994) bioecological model explains that the development of an individual is influenced by the multiple levels of interactions, either direct or indirect, that they encounter in their daily lives. The theory suggests that varying systems of environments that the individual is connected with can affect their development (Bronfenbrenner, 1994; Rosa \& Tudge, 2013). These levels, or systems, are as follows: the microsystem, the mesosystem, the exosystem, the macrosystem, and the chronosystem.

\section{Connecting Existing Literature to Bioecological Systems Model}

The bioecological model states that a person is influenced by various levels of interaction across many settings. This is in agreement with the main idea of the study, which purposes that the marital satisfaction a couple experiences is shaped by the various internal and external environments within which they live their lives. Existing literature supports the connections between the main components of the current study and the various levels of the bioecological systems model, most notably those of the microsystem and exosystem. In line with the exosystem is the idea that the workplace flexibility of a parent may influence the amount of time they are able to have at home caring for their child. In terms of the microsystem, the amount of time they have at home to provide parenting support will then likely impact how much support their spouse feels in the parenting duties. 


\section{Microsystem}

A married couple represents a microsystem, an intimate relationship within their immediate environment, where the individuals effect the continuing development and growth of one another (Bronfenbrenner, 1994). Using the lens of the bioecological model, it is understood that the individuals in a marriage hold influence over each other. Spending time together has been found to be one of the key factors of high marital satisfaction (Russell-Chapin, Chapin, \& Sattler, 2001), and is a way in which both members of the microsystem directly interact with one another and develop their perceptions about the quality of the relationship. However, spending time together can be especially strained in families with children with special needs. Parents of children with special needs spend more time taking their children to medical and therapy appointments and more time providing direct supervision to their children, which can reduce the amount of quality time spent with their spouse (Daire et al., 2011; Russell-Chapin et al., 2001).

While being able to actively interact in a positive manner with a spouse may improve the relationship between members of a microsystem, the unavailability or absence of this person from the microsystem is likely to detract from the quality of the relationship. Individuals who feel unsupported or disconnected from their spouse may even transfer this dissatisfaction to their roles as parents (Ato et al., 2015; Kersh et al., 2006), whereas couples who experience higher levels of marital satisfaction tend to be more supportive and involved as parents (Ato et al., 2015). This suggests that the connections and interactions experienced within the microsystem of a family strongly effect the well-being of all of its members. 
Children may be at a high risk for anxiety, aggression, and behavioral problems if they are subjected to high conflict between married parents (Morrison \& Coiro, 1999). In fact, some research has found that exposure to parental conflict can be more detrimental to children than the loss of a parent through divorce or death (Jekielek, 1998; Morrison \& Coiro, 1999). Unproductive parenting methods, a lack of warmth and attention to the child, and inconsistent discipline techniques within the parent-child dyad have also been attributed to marital discord among parents (Peris, Goeke-Morey, Cummings, \& Emery, 2008). In the instance of a divorce, both children and parents within the microsystem are impacted by it. Couples who divorce tend to have "a lower standard of living, have less wealth, and experience greater economic hardship than do married individuals" (Forste \& Heaton, 2004, p. 99). Greater rates of psychological distress, illnesses, alcohol use, and decreased emotional health are also found in divorced individuals more often than in married individuals (Forste \& Heaton, 2004). For children experiencing the divorce of their parents, there is a risk of behavioral, emotional, and mental and physical health problems in response to the division of the systems within their family (Fergusson et al., 2014; Weaver \& Schofield, 2015; Woody, 2009).

\section{Exosystem}

The exosystem indicates that an individual's development can be influenced by an external source where the individual is not present (Rosa \& Tudge, 2013). In terms of the current study, it is suggested that the flexibility of a parent's workplace can impact the resources available to the children and spouse of an individual. Balancing time and schedules is necessary in any family, however, in a family with children with special needs, the need for flexibility can be greater in order to provide the children with services 
they require. If parents are unable to take time off of work due to schedule rigidity or financial concern, they may be faced with choosing between their job and their children.

Due to increased hospital visits, parents of children with special needs have additional time and finance burdens to juggle. As many children with special needs require individualized care and services that children without special needs do not (e.g., respite care, assistive devices, and specialized medical professionals), parents of children with special needs may face challenges in meeting these extra requirements (Daire et al., 2011). Daire et al. (2011) found "the mean number of healthcare visits in a six-month period for children with special needs was 50.47 compared to 0.29 for children without special needs" (p.183). This increased financial burden can be as much as three times higher than the costs of caring for a child without special needs and may also strain the marital relationship if one parent must stay at home to care for the child, or if the family already had financial struggles before the birth of the child (Daire et al., 2011; Dobson \& Middleton, 1998). The impact of this conflict between parent and occupation represents circumstances that effect the child and the spouse even though they are not present, which is depicted within the exosystem of the bioecological systems model. If the working parent(s) do not have flexibility in the workplace they may risk missing income and losing their job and insurance, which would drastically impact available family resources. Even still, these parents may miss out on opportunities to take their children to therapies they may require. 


\section{Children with Special Needs}

The number of children who have a special needs diagnosis in the United States gives credence to the necessity of studying the family lives of these such children. More than 6 million children between the ages of three and 21 (about 13\% of all public school students) required special education courses for the 2013-2014 school year (National Center for Educational Statistics, 2016). Within these same numbers, 35\% of students had a specific learning disability, $21 \%$ had a speech or language disability, $13 \%$ were classified as having 'other health impairments,' $8 \%$ had a diagnosis of autism, and the remaining conditions reported occurred within $7 \%$ or less of the students with special needs (National Center for Educational Statistics, 2016). These developmental disabilities include deficiencies in language, learning, and physical and behavioral functioning, which arise in early development and likely last through the individual's entire life (Centers for Disease Control and Prevention, 2015). One study found that in the major metropolitan areas of the United States, the dominant disability type reported in young children is that of cognitive difficulty, defined as an acute problem with concentrating, decision making, and memory (Brault, 2011).

Based on these statistics, it is evident that many children require additional services and accommodations beyond what is typically provided to children without a special needs diagnosis. Additionally, the families working to provide this extra care for their children within the home face more stress and financial strain then families with children without developmental concerns (Thurston et al., 2011). Understanding the challenges that families face when raising a child with special needs can help researchers 
and practitioners create effective treatment and therapy plans that benefit the individual child, the parenting unit, and the family as a whole.

Parenting a child with special needs may be challenging at times, however there can be many positive outcomes as well (Thurston et al., 2011). Families can adapt to the challenges and show great resilience, which increases the well-being of all members of the family unit, and many "families with special needs children do well despite the required increase in family resources such as time, energy and coping strategies" (Thurston et al., 2011, p.264)., Many families of children with special needs report quality of life on par with families with children without special needs (Daire et al., 2011) and it is suggested that caring for a child with special needs may not be as detrimental to marital satisfaction as once thought (Wieland \& Baker, 2010).

\section{Perceived Spousal Support in Parenting}

Feeling supported in the parenting role is essential for mothers and fathers of children of all functioning and ability levels (Cohen, Zeedyk, Tipton, Rodas, \& Blacher, 2016). This support reduces stress for the individual parents, improves family functioning, and creates consistency for the children within these families (Holland \& McElwain, 2013). Parents who feel supported by one another are likely to perform better in their roles as parents and utilize effective and nurturing parenting styles that are in agreement with how both parents believe the children should be reared (Bristol et al., 1988; Wieland \& Baker, 2010). The feeling of being supported can even reduce the risk of depression in parents and can indicate high levels of marital satisfaction (Wieland \& Baker, 2010). 
As Bristol et al. (1988) found, expressive support from a spouse is a strong predictor of the quality of parenting that the child will receive. Expressive support is considered to be a person's perception of how appreciated, understood, included, and loved they feel by their spouse (Bristol et al., 1988). This finding of the importance of spousal support was observed for parents of children with special needs as well as for parents of children without special needs (Bristol et al., 1998; Wieland \& Baker, 2010). This perception of support is informed by how the parent perceives the other's involvement, how the other behaves, and the satisfaction felt within the current relationship (Priem et al., 2009). Parents who trust one another to provide the best level of care for their child are likely to feel higher amounts of marital love, and those with higher levels of marital connection are likely to trust the other partner in the parenting position more (Belsky, Putnam, \& Crnic, 1996; Holland \& McElwain, 2013). This finding is also true in the reverse, whereas couples who have highly distressed marriages are likely to engage ineffectively in their parenting practices (Belsky et al., 1996; Holland \& McElwain, 2013).

Considering the notion that the amount of support a parent feels influences the quality of parenting that a child will receive, it is imperative to examine how each parent is interpreting the involvement of their co-parent. Measuring perceived spousal support in parenting can be accomplished by self-report measures which allow the participant to describe how much and in what ways their spouse helps with parenting responsibilities. 


\section{Perceived Job Flexibility}

Job flexibility has been defined in various ways in past studies. For some, the concept of job flexibility has been described as the methods that human resource departments utilize in order to help workers balance work and non-work responsibilities, and others see it as the amount of choice that a worker has in designing and altering central facets of their working roles (Allen et al., 2013; Bal \& De Lange, 2015; Hill et al., 2008). In this current study, the term will be defined as it relates to time, and can be thought of as places of work "allowing employees to have flexible schedules that enable them to better manage work and personal or family life" (Galinsky, Sakai, \& Wigton, 2011, p. 142-143).

For families with children, having some degree of flexibility in the workplace may contribute greatly to family functioning. While it is necessary for most families in modern society to have at least one employed parent, many families now have both parents working outside of the home (Hill et al., 2001). The income is vital for family stability, however, when children are occasionally sick or have chronic conditions, someone needs to be able to stay home to care for them or take them to the doctor. Unfortunately, this is not always possible, as some families cannot afford to take unpaid time off, which then leaves the parents depending on others to help care for their children in the interim.

In dual-earner households, the parents may need to rely on child care centers to care for their children during work hours. Child care facilities typically hold standard hours of operation and may not be able to accommodate parents on days where they need to work overtime to catch up on missed work or to get ahead in their duties (Press \& 
Fagan, 2006). This can create conflict, as parents may have to negotiate with each other to determine who will be responsible for picking up the children, as well as finding leniency in their working hours if they are needed to attend to the children (Press \& Fagan, 2006). However, if parents are able to take turns or compromise on when each parent needs to be available for child care so that the other parent can work, the individuals may experience higher levels of perceived parenting support (Press \& Fagan, 2006).

Having flexibility in the workplace can also improve the job satisfaction, work performance, and health of the employee (Michel \& Michel, 2015; Vandello, Hettinger, Bosson, \& Siddiqi, 2013). For those who work nonstandard hours, work schedules which are not created around the needs of their family can increase stress, increase work-family role conflict, reduce the amount of time spent with children, and decrease marital satisfaction (Henly et al., 2006; McNall et al., 2009). As of 2003, nearly 40 percent of American workers worked nonstandard, daytime hours - making the need to create more schedule flexibility that takes the individual into account even more necessary (Henly et al., 2006).

Final Conclusions about Existing Literature

Previous literature has examined many factors that impact marital satisfaction and highlight risk factors for divorce or marital discord (Balderrama-Durbin, Snyder, \& Balsis, 2015; Daugherty \& Copen, 2016; Gottman, Coan, Carrere, \& Swanson, 1998; Holland \& McElwain, 2013; Kazdin, 2010; Wymbs, 2008). The families of children with special needs have also been observed as the subjects of this research, with a focus on the unique dynamics of the relationships between these children and their parents (Daire et 
al., 2011; Hartley et al., 2010; Pickar \& Kaufman, 2015). Considerations of spousal support in parenting practices and the schedule flexibility of workplaces have likewise been acknowledged in studies concerning job, life, and marital satisfaction of individuals (Belsky et al., 1996; Bristol et al., 1988; Hill et al., 2001; Michel \& Michel, 2015; Vandello et al., 2013; Wieland \& Baker, 2010), however, there is a deficiency in the research concerning how interconnected the concepts of perceived job flexibility and spousal support in parenting may be to the overall marital satisfaction of parents with children with special needs. The current study aims to fill this gap in the literature by examining how the role of perceived spousal support in parenting mediates the relationship between perceived job flexibility and the marital satisfaction of parents with children with special needs.

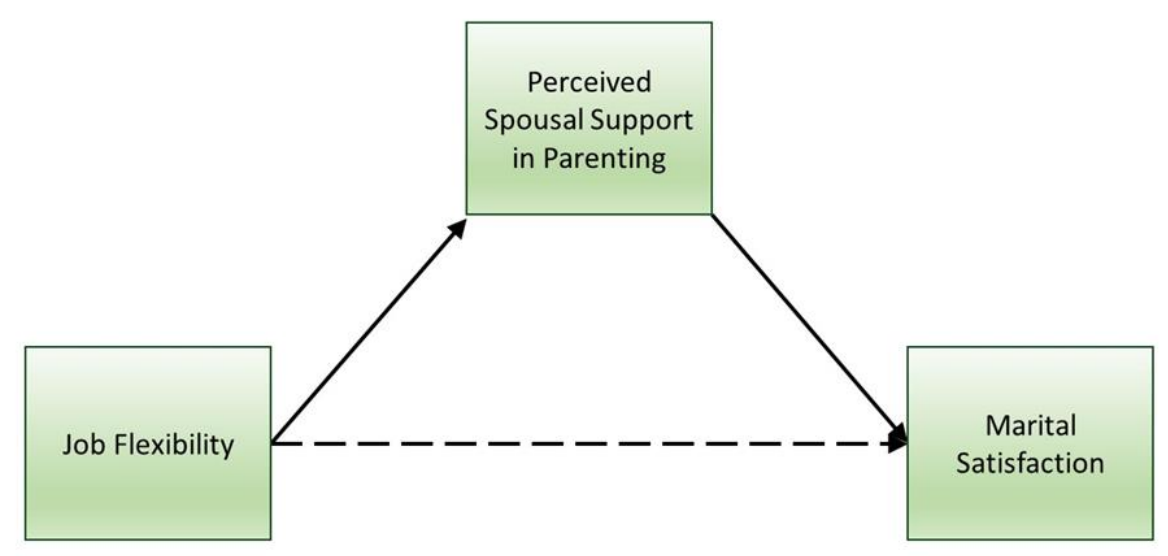

Figure A1. Hypothesized mediation model of the relationship between job flexibility, perceived spousal support in parenting, and marital satisfaction. 


\section{Hypotheses}

The reviewed literature has informed the creation of the following hypotheses: H1. Marital satisfaction levels will be higher for individuals that report that one or both parents have perceived job flexibility.

H2. Marital satisfaction levels will be higher for individuals that report higher levels of perceived spousal support in parenting responsibilities.

H3. Perceived spousal support in parenting responsibilities will be higher for individuals that report that one or both parents have perceived job flexibility.

H4. Perceived spousal support in parenting responsibilities will mediate the relationship between perceived job flexibility and marital satisfaction.

\section{METHODOLOGY}

The purpose of conducting this quantitative research is to examine factors that influence the marital satisfaction of parents of children with special needs diagnoses, specifically the influences of perceived spousal support in parenting and job flexibility. A self-report survey questionnaire will be used to collect data from participants who are at least 18 years of age and married with children. Data will be examined using linear regression and a mediation model. After presenting participants with a consent form and verifying that they meet the required criteria, the participants will complete an online questionnaire which addresses demographic information, marital satisfaction, spousal perceptions of parenting support, and job flexibility.

\section{Sample}

Individuals at least 18 years of age who are married and have a child or children with special needs will be the target population of this study. This survey aims to include 
over 100 participants as an appropriate sample size for obtaining a low margin of error for a study of this nature (Burmeister \& Aitken, 2012). This study will be available to participants meeting the aforementioned criteria without any stipulations on gender, sex, sexual orientation, race, ethnicity, or religious beliefs.

The survey will be distributed electronically and will be hosted through the Qualtrics web server. As this survey will exist online, it will be shared with participants via social media websites (Facebook.com, Reddit.com) and through the email newsletters of the University of Southern Mississippi (USM) and the National Council on Family Relations (NCFR). Social media groups related to special needs and parenting will be contacted specifically. Utilizing the internet as the medium for distribution allows for the survey to be administered with a great deal of time flexibility, at a quick rate, with low cost, and with the potential to obtain a large sample size (Benfield \& Szlemko, 2006; Best, Krueger, Hubbard, \& Smith, 2001). Participants will be able to complete the survey at their own leisure, will not be hindered by waiting for a mail-in survey, and will experience no financial deficits outside of their pre-existing expenses for internet service. A potential limitation of using this medium is that while the sample is likely to be diverse, it may not be representative, considering that the majority of internet users come from higher educational and socioeconomic backgrounds (Best, et al., 2001). Additionally, bias can arise as people are more likely to complete surveys about topics which appeal to them (Eysenbach \& Wyatt, 2002). Specifically, women are likely to complete this survey at higher rates than men because women are more apt to complete surveys regarding health concerns (Eysenbach \& Wyatt, 2002), under the umbrella of which this survey can be considered. 
An example of the announcement flyer promoting the study can be found in the Appendix. This study will rely on snow-ball sampling and word of mouth in order to reach the desired number of participants. Those who choose to complete the survey will be reminded that their participation is voluntary and that they may choose to exit the survey at any time.

As this survey will be distributed to human participants, conducting the study in an ethical manner is mandatory. The first step in protecting the subjects will be to make them aware of any possible risks associated with participating in the study. While there should be no major risks associated with completing the survey, the questionnaire may ask questions that feel personal to individuals. Questions related to parenting support and marital satisfaction have the potential to make participants uncomfortable or trigger unpleasant memories. Participants will be advised to consider this in the consent agreement before entering into the survey, however they will also be reminded that they may leave the survey at any time if they feel uncomfortable and participants will be able to skip any question that they do not wish to answer. Additionally, resources for counseling or support for a child with special needs will be provided at the beginning and the conclusion of the survey.

Another consideration in providing ethical treatment is the degree of privacy that the participants will receive. All participants will be informed of the purpose of the survey, their rights in participating, and the confidentiality that they can expect. Participants will not provide any identifiable information and all data received will be linked with a number instead of any name or email address. After the study is completed, all information that was collected online will be transferred to a data analysis program on 
a password protect computer before being electronically deleted. This study will follow all guidelines set by the University of Southern Mississippi' Institutional Review Board (IRB).

\section{Measures}

This study will be conducted in the format of a self-report, survey questionnaire. The introduction of the survey will provide participants with a consent agreement and a prompt to verify that they are at least 18 years of age. Participants who signify that they are not at least 18 years of age will be released from the survey immediately. The consent form will be electronically displayed and agreed to before the individual can begin the questionnaire. The consent form will inform the participants that the data they provide will be kept confidential, that participating in the survey is completely voluntary, and that they may leave the survey at any time. An example of the consent form can be found in the Appendix.

Demographic Information. Participants will be asked to indicate their current location (country/state), sex, ethnicity, race educational level, age, length of current marriage, and income. These questions are similar in format to items on current U.S. Census questionnaires can be found in the Appendix. The purpose of collecting information about the participant's location, sex, ethnicity, race, education level, age, length of current marriage, and income is to help determine potential confounding variables that may influence the interpretation of results. Data on these descriptors may also be helpful in spotting trends recognized in previous research. For example, families with children with special needs tend to spend more money on care for their child than those with children without special needs (Thurston et al., 2011). Differences in levels of 
income could impact how much stress each family feels when meeting these needs and may prove to be notable in interpreting the results of this survey. Additionally, many previous studies reflect the viewpoint of mothers of children with special needs (Blacher et al., 1997; Hoare, Harris, Jackson, \& Kerley, 1998), so being able to determine the sex of the participant may also influence data interpretations.

Additionally, participants will be asked to provide non-identifiable information about their child or children. Participants will be asked how many children are living in the home, how many children with a special needs diagnosis they have, the age of their child with special needs, and the specific diagnosis of their child with special needs. Participants will be asked how many medical and therapy appointments their child has attended in the last 30 days, the number of hours spent at said appointments in the last 30 days, and the approximate amount of appointments in which the participant joins their child. For participants with more than one child with a special needs diagnosis, they will be able to answer the aforementioned questions for each child. Just as the demographic mentioned above, these descriptive questions may also be helpful in recognizing trends seen in previous studies. For example, parenting has been shown to be more stressful within families who have children who are more dependent or require more medical and therapy appointments than children who require less intervention (Algood, Harris, \& Hong, 2013; Hodapp, Ly, Fidler, \& Ricci, 2001). Also, within families raising a child with special needs, there is less time for parents to spend together as marital couple (Wayne \& Krishnagiri, 2005), so there may be a relationship between marital satisfaction and time spent taking children to appointments. 
Measures of Marital Satisfaction. Martial satisfaction will be measured using the Marital Adjustment Test (MAT), which consists of 15 items (Locke \& Wallace, 1959). The MAT questions are designed to "assesses general happiness with a marriage, as well as the extent of agreement or disagreement between partners on issues such as finances, recreation, affection, friends, sex, philosophy of life, and dealing with in-laws" (Priem et al., 2009). This 15 item measure consists of 7 multiple choice questions, 1 question which uses a Likert scale to prompt the participant to indicate on a dotted line where they would rate their current happiness in their marriage from very unhappy to perfectly happy, and 8 questions which use a 6-point Likert scale to rate the degree to which their spouse and they agree on various topics, with possible responses ranging from always agree to always disagree. Respondents receive scores which vary between the items, with a higher overall score representing a higher degree of marital satisfaction (Ato et al., 2015; Saxbe et al., 2008). This measure was chosen because of its high internal reliability (.90) and the high frequency with which it has been utilized in previous work, such as that of Ato et al., (2015) and Saxbe et al., (2008).

Measures of Perceived Spousal Support in Parenting. Perceived spousal support in parenting will be measured using the Parenting Alliance Inventory (Abidin \& Brunner, 1995). This consists of 20 items intended to assess the trust the respondent has in their partner's parenting capabilities, as well as the support they feel that they receive from their partner in the parenting process (Abidin \& Brunner, 1995; Holland \& McElwain, 2013). The items are on a 5-point Likert scale and participants select how much they agree with a statement within the range of choices, with 1 indicating strong disagreement and 5 indicating strong agreement; with a higher score being associated with higher 
perceived support. This measure was chosen due to the high reliability (.97) and frequency of use in previous studies, with examples including the work of Abidin \& Brunner (1995) and Holland \& McElwain (2013).

Measures of Perceived Job Flexibility. Participants will be asked to identify their current employment status, their current occupation, and the average amount of hours worked per week. If they are unemployed, questions pertaining to their own workplace will be omitted. Additionally, participants will be asked to identify their spouse's current employment status, their spouse's current occupation, and the average amount of hours their spouse works per week. If their spouse is unemployed, questions pertaining to their spouse's workplace will be omitted. Participants will be asked to rate their perception of their workplace's flexibility if they indicated that they are employed. Participants will be asked to rate their perception of their spouse's workplace's flexibility if they indicated that their spouse is employed.

Job flexibility of the participant will be ascertained using Rothausen's (1994) measure of job flexibility. The measure consists of a 5-point Likert scale in which the participants will indicate their satisfaction with the 5 presented statements on a scale ranging from 1 (strongly dissatisfied) to 5 (strongly satisfied); with a higher score indicating a higher level of perceived job flexibility. The statements are as follows: "1. The extent to which management accommodates family responsibility and needs without negative consequences, 2 . The opportunity to perform your job well and yet be able to perform home-related duties adequately, 3 . The ease of getting time off for family as needed, 4. The opportunity to do part-time or flex-time work without being penalized, and 5. The amount of flexibility in work scheduling" (Rothausen, 1994). In the event that 
both the participant and their spouse are employed, the scores from the participant and their spouse on the job flexibility measure will be averaged together to create one numeric response. This measure was chosen due to the high reliability (.87) and frequency of use in previous studies, with examples including the work of Rothausen (1994) and Michel \& Michel (2015).

Scoring Measures. Each section of the given survey will be calculated according to the affiliated guidelines from which the section was derived. Marital satisfaction will be measured using the complete, 16-item MAT. The data derived from this portion will be coded and scored using the specific rubric of the MAT to find an averaged response indicating the level of marital satisfaction felt. Job flexibility will be measured using Rothausen's (1994) measure of job flexibility. The data accumulated from this portion of the survey will be coded and scored by deriving an average numbered response to indicate the level of flexibility the individual experiences in their workplace, as well as the amount of job flexibility that their spouse receives in their respective workplace. Perceived parental support of a spouse will be measured using the complete version of the 20-item PAI. The data acquired from this portion of the survey will be calculated into an average score of perceived parental support from a spouse. The data will be organized and coded in the most efficient manner possible in order to produce concise results.

\section{Procedures}

This study will be comprised of a self-report survey measure designed to examine demographic information, marital satisfaction, spousal perceptions of parenting support, and job flexibility of parents of children with special needs diagnoses. The questionnaire will be distributed online so that participants may complete the survey in any location or 
at any time that is convenient for them. The items on the questionnaire will be aimed towards addressing the research questions and will be conducted in an ethical manner.

There is a total of 75 items on the questionnaire when the respondent and their spouse are both employed and have only one child with a special needs diagnosis. If either the participant or their spouse is reported to be unemployed, the participant will not answer job flexibility questions for the unemployed person, and will only receive 66 questions. In the event that both the participant and their spouse are reported to be unemployed, the participant will not answer any job flexibility questions, and will only receive 57 questions. For participants who have more than one child, they will answer 9 more questions for each additional child reported. In the instance that the participant does not live in the United States, they will not have to indicate which state they live in, and will therefore have 1 less question to answer.

Consent Procedure. The first page of the survey will contain the consent agreement, which participants must agree to in order to complete the survey. Participants will be informed that the survey is voluntary, that they may leave the survey at any time, and that they do not have answer any questions which cause them any unease. By agreeing to continue to the survey, participants will also be certifying that they are at least 18 years of age. Within the consent form, links to websites that may be resources for participants will be provided in the circumstance that the participant requires counseling or additional information.

Survey Procedure. Participants will begin the survey after indicating that they have reviewed the consent form and verified that they are at least 18 years old. The first section of the survey will contain questions that will record demographic information 
including the following: state/country of residence, sex, ethnicity, race, educational level, age, and income. The next section will ask about employment status of the participant and of the spouse of the participant. If participants are not employed, or if their spouse is not employed, skip logic will be utilized in the survey program as to avoid the participants being prompted to answer questions which do not pertain to them. Following employment, participants will complete the marriage portion of the questionnaire. After indicating the length of their current marriage, participants will complete the MAT. Once this section has been completed, participants will be directed to the section regarding children and parenting.

Participants will indicate how many children they have and then will answer whether they have any children with special needs. If the participant has a child with special needs, they will be prompted to enter information concerning age of the child and therapies and appointments attended. The participant will be able to enter the information for multiple children with special needs if necessary. The participant will then be prompted to complete the PAI with their child/children with special needs in mind. If the participant does not have a child with special needs, the questions regarding appointments and therapies will be skipped and they will be instructed to complete the PAI -without any prompt language about children with special needs. This will conclude the survey and the participant will be thanked for contributing. Links for supplemental resources that will be on the consent form will also be provided at the end of the survey.

Data will be collected from the Qualtrics survey hosting website and will be downloaded from IBM SPSS Statistics 24 for analysis. There will be no personally identifying information to link participants to their surveys and all entries will be 
represented by numbers. All data will be password protected in an additional effort to ensure confidentiality. The recorded data from the surveys will be stored on a password protected computer after the completion of the survey. Additionally, the link to the online survey and all online data will be deleted after all information has been transferred to the analysis program.

\section{Analysis of data}

The collected data from this study is largely quantitative in nature. All demographic information will be organized and examined through descriptive statistical analysis. Data pertaining to marital satisfaction, perceived spousal support in parenting, and job flexibility will be analyzed and interpreted through the mediation model and linear regression in order to address the proposed research questions. Connections between the variables and the influences they hold over one another will be examined.

Descriptive Statistical Analysis. Data collected from the demographic section of the survey will be interpreted though descriptive statistical analysis. Descriptive statistics from all study variables will be reviewed to observe how data is distributed across the sample. Additionally, the descriptive statistics will be used as control variables as necessary in completing further analyses.

Correlations. Correlations among study variables will be explored to identify potential associations. Connections between perceived job flexibility, perceived spousal support in parenting, and marital satisfaction will be examined before imploring multiple regression or mediation. Additionally, descriptive variables, such as sex, working hours per week, and number of children with a special needs diagnosis, will be analyzed with 
factors such as perceived job flexibility, marital satisfaction, and perceived spousal support in parenting, to determine any correlation.

Multiple Regression Analysis. Multiple regression will be used to associate marital satisfaction with job flexibility and spousal support in parenting, while controlling for demographics. This method of analysis will be utilized to examine whether marital satisfaction levels can be predicted based on perceived job flexibility and perceived spousal support in parenting. Multiple regression may also be employed as necessary to determine the value of any other variables of interest within the dataset.

Mediation Model Analysis. The data collected during this study will be analyzed through a mediation model which suggests that perceived parental support of a spouse mediates the relationship between job flexibility and marital satisfaction (see Figure 1). The mediation model analysis consists of four steps which must be followed in order to determine an indirect association between perceived job flexibility and marital satisfaction through perceived spousal support in parenting.

The first step requires that the causal variable is correlated with the outcome variable (Baron \& Kenny, 1986; James \& Brett, 1984; Judd \& Kenny, 1981). Level of job flexibility will be observed as it relates to marital satisfaction. These variables must be related in order to continue to the next step. The second step indicates that the causal variable is correlated with the mediator (Baron \& Kenny, 1986; James \& Brett, 1984; Judd \& Kenny, 1981). Level of job flexibility will be examined as it relates to perceived spousal support in parenting. These variables must be correlated in order to continue the analysis. 
The third step requires that the mediator has an effect on the outcome variable (Baron \& Kenny, 1986; Judd \& Kenny, 1981). Perceived spousal support in parenting will be observed as it relates to marital satisfaction. These variables should be correlated, however the next step is crucial in order to determine and level of causality. The fourth step requires that the mediating variable be shown to completely mediate the relationship between the other two variables (Baron \& Kenny, 1986; James \& Brett, 1984; Judd \& Kenny, 1981). Perceived spousal support in parenting will be examined as it influences the relationship between job flexibility and marital satisfaction. Following completion of this analysis, the results will be reviewed in order to ensure that all research questions were addressed and all protocol was followed accurately. If the mediation hypothesis is correct, the link between perceived job flexibility and marital satisfaction will be nonsignificant when spousal support in parenting is in the model. 


\section{REFERENCES}

Abidin, R. R. \& Brunner, J. F. (1995). Development of a parenting alliance inventory. Journal of Clinical Child Psychology, 24(1), 31-40. doi:

10.1207/s15374424jccp2401_4

Algood, C. L., Harris, C., \& Hong, J. S. (2013). Parenting success and challenges for families of children with disabilities: An ecological systems analysis. Journal of Human Behavior in the Social Environment, 23(2), 126-136. doi:

10.1080/10911359.2012.747408

Allen, T. D., Johnson, R. C., Kiburz, K. M., \& Shockley, K. M. (2013). Work-family conflict and flexible work arrangements: Deconstructing flexibility. Personnel Psychology, 66(2), 345-376. doi: 10.1111/peps.12012

Ato, E., Galián, M. D., \& Fernández-Vilar, M. A. (2015). The moderating role of children's effortful control in the relation between marital adjustment and parenting. Journal of Child and Family Studies, 24(11), 3341-3349. doi: 10.1007/s10826-015-0136-4

Bal, P. M. \& De Lange, A. H. (2015). From flexibility human resource management to employee engagement and perceived job performance across the lifespan: A multisample study. Journal of Occupational and Organizational Psychology, 88(1), 126-154. doi: 10.1111/joop.12082

Balderrama-Durbin, C., Snyder, D. K., \& Balsis, S. (2015). Tailoring assessment of relationship distress using the marital satisfaction inventory-brief form. Couple and Family Psychology: Research and Practice, 4(3), 127-135. doi:

$10.1037 / \mathrm{cfp} 0000042$ 
Barkley, R. A., Fischer, M., Edelbrock, C., \& Smallish, L. (1991). The adolescent outcome of hyperactive children diagnosed by research criteria-III. Motherchild interactions, family conflicts and maternal psychopathology. Journal of Child Psychology and Psychiatry, 32(2), 233-255.

Baron, R. M. \& Kenny, D. A. (1986). The moderator-mediator variable distinction in social psychological research: Conceptual, strategic, and statistical considerations. Journal of Personality and Social Psychology, 51(6), 1173.

Belsky, J., Putnam, S., \& Crnic, K. (1996). Coparenting, parenting, and early emotional development. In J. P. McHale, P. A. Cowan, J. P. McHale \& P. A. Cowan (Eds.), Understanding how family-level dynamics affect children's development: Studies of two-parent families. (pp. 45-55). San Francisco, CA, US: Jossey-Bass.

Benfield, J. A., \& Szlemko, W. J. (2006). Internet-based data collection: Promises and realities. Journal of Research Practice, 2(2), d1.

Best, S., Krueger, B., Hubbard, C., \& Smith, A. (2001). An assessment of the generalizability of internet surveys. Social Science Computer Review, 19(2), 131145.

Blacher, J., Lopez, S., Shapiro, J., \& Fusco, J. (1997). Contributions to depression in Latina mothers with and without children with retardation: Implications for caregiving. Family Relations, 325-334.

Bowen, M. (1978). Family therapy in clinical practice. Jason Aronson, New York.

Brault, M. W. (2011). School-aged children with disabilities in US metropolitan statistical areas: 2010. American Community Survey Briefs. ACSBR/10-12. US Census Bureau. 
Bristol, M. M., Gallagher, J. J., \& Schopler, E. (1988). Mothers and fathers of young developmentally disabled and nondisabled boys: Adaptation and spousal support. Developmental Psychology, 24(3), 441.

Bronfenbrenner, U. (1994). Ecological models of human development. Readings on the development of children, 2, 37-43.

Brown, S, L. \& Booth, A. (2002). Stress at home, peace at work: A test of the Time Bind Hypothesis. Social Science Quarterly, 83(4). 905-920. doi: 10.1111/15406237.00121

Burmeister, E. \& Aitken, L. M. (2012). Sample size: How many is enough? Australian Critical Care, 25(4), 271-274.

Centers for Disease Control and Prevention. (2015). Developmental disabilities. Retrieved October 15, 2016, 2016, from http://www.cdc.gov/ncbddd/developmentaldisabilities/facts.html

Cohen, S. R., Zeedyk, S. M., Tipton, L. A., Rodas, N. V., \& Blacher, J. (2016). Fathers of children with or without ID: Understanding long- term psychological symptoms. Journal of Intellectual Disability Research, 60(4), 295-307. doi: $10.1111 /$ jir. 12232

Copen, C. E., Daniels, K., \& Mosher, W. D. (2013). First premarital cohabitation in the United States: 2006-2010 national survey of family growth. National health statistics reports, 64(64), 1-15.

Council on Clinical Affairs. (2012). Definition of special health care needs. Reference Manual, 37(6), 15-16. 
Crettenden, A., Wright, A., \& Skinner, N. (2014). Mothers caring for children and young people with developmental disabilities: Intent to work, patterns of participation in paid employment and the experience of workplace flexibility. Community, Work \& Family, 17(3), 244-267. doi: 10.1080/13668803.2014.923816

Daire, A. P., Munyon, M. D., Carlson, R. G., Kimemia, M., \& Mitcham, M. (2011). Examining distress of parents of children with and without special needs. Journal of Mental Health Counseling, 33(2), 177-188. doi: 10.17744/mehc.33.2.qu73p03176337xx1

Daugherty, J. \& Copen, C. (2016). Trends in attitudes about marriage, childbearing, and sexual behavior: United States, 2002, 2006-2010, and 2011-2013. National health statistics reports (92), 1-11.

Dobson, B. \& Middleton, S. (1998). Paying to care: The cost of childhood disability: YPS.

Elwood, R. W. \& Jacobson, N. S. (1982). Spouses' agreement in reporting their behavior interactions: A clinical replication. Journal of Consulting and Clinical Psychology, 50(5), 783-784.

Eysenbach, G., \& Wyatt, J. (2002). Using the Internet for surveys and health research. Journal of Medical Internet Research, 4(2), e13.

Fergusson, D. M., McLeod, G. F. H., \& John Horwood, L. (2014). Parental separation/divorce in childhood and partnership outcomes at age 30. Journal of Child Psychology \& Psychiatry, 55(4), 352-360. doi: 10.1111/jcpp.12107 
Fidler, D. J., Hodapp, R. M., \& Dykens, E. M. (2000). Stress in families of young children with Down syndrome, Williams syndrome, and Smith-Magenis syndrome. Early Education and Development, 11, 395-406.

Fincham, F. D. \& Beach, S. R. (2010). Marriage in the new millennium: A decade in review. Journal of Marriage and Family, 72(3), 630-649.

Forste, R. \& Heaton, T. B. (2004). The divorce generation: Well-being, family attitudes, and socioeconomic consequences of marital disruption. Journal of Divorce \& Remarriage, 41(1-2), 95-114. doi: 10.1300/J087v41n01_06

Galinsky, E., Sakai, K., \& Wigton, T. (2011). Workplace flexibility: From research to action. The Future of Children, 21(2), 141-161. doi: 10.1353/foc.2011.0019

Gerstel, N. \& Clawson, D. (2014). Class advantage and the gender divide: Flexibility on the job and at home. American Journal of Sociology, 120(2), 395-431. doi: 00029602/2015/12002-0003

Gottman, J. M. (2014). What predicts divorce?: The relationship between marital processes and marital outcomes. Psychology Press.

Gottman, J. M., Coan, J., Carrere, S., \& Swanson, C. (1998). Predicting marital happiness and stability from newlywed interactions. Journal of Marriage and the Family, 60(1), 5-22. doi: 10.2307/353438

Hartley, S. L., Barker, E. T., Seltzer, M. M., Floyd, F., Greenberg, J., Orsmond, G., \& Bolt, D. (2010). The relative risk and timing of divorce in families of children with an autism spectrum disorder. Journal of Family Psychology, 24(4), 449. 
Henly, J. R., Shaefer, H. L., \& Waxman, E. (2006). Nonstandard work schedules: Employer- and employee-driven flexibility in retail jobs. Social Service Review, 80(4), 609-634. doi: 10.1086/508478

Hill, E. J., Grzywacz, J. G., Allen, S., Blanchard, V. L., Matz-Costa, C., Shulkin, S., \& Pitt-Catsouphes, M. (2008). Defining and conceptualizing workplace flexibility. Community, Work \& Family, 11(2), 149-163. doi: 10.1080/13668800802024678

Hill, E. J., Hawkins, A. J., Ferris, M., \& Weitzman, M. (2001). Finding an extra day a week: The positive influence of perceived job flexibility on work and family life balance. Family Relations: An Interdisciplinary Journal of Applied Family Studies, 50(1), 49-58. doi: 10.1111/j.1741-3729.2001.00049.x

Hoare, P., Harris, M., Jackson, P., \& Kerley, S. (1998). A community survey of children with severe intellectual disability and their families: psychological adjustment, carer distress and the effect of respite care. Journal of Intellectual Disability Research, 42(3), 218-227.

Hodapp, R. M., Ly, T. M., Fidler, D. J., \& Ricci, L. A. (2001). Less stress, more rewarding: parenting children with Down syndrome. Parenting: Science and Practice, 1(4), 317-337.

Hofferth, S. L. \& Sandberg, J. F. (2001). How American children spend their time. Journal of Marriage and Family, 63(2), 295-308. doi: 10.1111/j.17413737.2001.00295.x

Hoffman, J. P. (2006) Family structure, community context, and adolescent problem behaviors. Journal of Youth \& Adolescence, 35, 867-880. doi: 10.1007/s10964006-9078-X 
Holland, A. S. \& McElwain, N. L. (2013). Maternal and paternal perceptions of coparenting as a link between marital quality and the parent-toddler relationship. Journal of Family Psychology, 27(1), 117-126. doi: 10.1037/a0031427

Iobst, E. A., Alderfer, M. A., Sahler, O. J. Z., Askins, M. A., Fairdough, D. 1., .. \& Noll, R. B. (2009). Brief report: Problem solving and maternal distress at the time of a child's diagnosis of cancer in two-parent versus lone-parent households. Journal of Pediatric Psychology, 34(8), 817-821. doi: 10.1093/jpepsy/jsn140

Jablonska, B. \& Lindberg, L. (2007) Rish behaviours, vicitmisation and mental distress among adolescents in different family structures. Social Psychiatry \& Psychiatric Epidemiology, 42, 686-663. doi: 10.1007/s00127-007-0210-3

James, L. R. \& Brett, J. M. (1984). Mediators, moderators, and tests for mediation. Journal of Applied Psychology, 69(2), 307.

Jekielek, S. M. (1998). Parental conflict, marital disruption and children's emotional wellbeing. Social Forces, 76(3), 905-936. doi: 10.2307/3005698

Jiang, Y., Terhorst, L., Donovan, H. S., Weimer, J. M., Choi, C. J., ... \& Sherwood, P. R. (2013). Locke-Wallace short marital-adjustment test: Psychometric evaluation in caregivers for persons with primary malignant brain tumor. Journal of Nursing Measurement 21(3), 502-515. doi: 10.1891/1061-3749.21.3.502

Judd, C. M. \& Kenny, D. A. (1981). Process analysis estimating mediation in treatment evaluations. Evaluation review, 5(5), 602-619.

Karney, B. R. \& Bradbury, T. N. (1997). Neuroticism, marital interaction, and the trajectory of marital satisfaction. Journal of Personality and Social Psychology, 72(5), 1075-1092. 
Kasari, C. \& Sigman, M. (1997). Linking parental perceptions to interactions in young children with autism. Journal of Autism and Developmental Disorders, 27, 39-57.

Kazdin, A. E. (2000). Marriage \& divorce. Encyclopedia of Psychology. Retrieved October 25, 2016

Kersh, J., Hedvat, T. T., Hauser-Cram, P., \& Warfield, M. E. (2006). The contribution of marital quality to the well-being of parents of children with developmental disabilities. Journal Of Intellectual Disability Research: JIDR, 50(Pt 12), 883893.

Locke, H. J. \& Wallace, K. M. (1959). Short marital-adjustment and prediction tests: Their reliability and validity. Marriage and Family Living, 21(3), 251-255. doi: $10.2307 / 348022$

McCrae, R. R., Stone, S. V., Fagan, P. J., \& Costa, Jr. P. T. (1998). Identifying causes of disagreement between self-reports and spouse ratings of personality. Journal of Personality, 66(3), 285-313.

McDermott, R., Fowler, J. H., \& Christakis, N. A. (2013). Breaking up is hard to do, unless everyone else is doing it too: Social network effects on divorce in a longitudinal sample. Social Forces, 92(2), 491-519.

McNall, L. A., Masuda, A. D., \& Nicklin, J. M. (2009). Flexible work arrangements, job satisfaction, and turnover intentions: The mediating role of work-to-family enrichment. The Journal of Psychology: Interdisciplinary and Applied, 144(1), 61-81. doi: 10.1080/00223980903356073

Michel, R. D. J.\& Michel, C. E. J. (2015). Work schedule flexibility, work-family enrichment and job satisfaction. Journal of Behavioural Sciences, 25(1), 78-90. 
Minde, K., Eakin, L., Hechtman, L., Ochs, E., Bouffard, R., Greenfield, B., \& Looper, K. (2003). The psychosocial functioning of children and spouses of adults with ADHD. Journal of Child Psychology and Psychiatry, 44(4), 637-646. doi: $10.1111 / 1469-7610.00150$

Morrison, D. R. \& Coiro, M. J. (1999). Parental conflict and marital disruption: Do children benefit when high-conflict marriages are dissolved? Journal of Marriage and the Family, 61(3), 626-637. doi: 10.2307/353565

National Center for Educational Statistics. (2016). Children and youth with disabilities. Retrieved October 15, 2016, 2016, from http://www.cdc.gov/ncbddd/developmentaldisabilities/facts.html

National Center for Health Statistics. (2016). Marriage and divorce. Retrieved October 25, 2016, from http://www.cdc.gov/nchs/fastats/marriage-divorce.htm

Peris, T. S., Goeke-Morey, M. C., Cummings, E. M., \& Emery, R. E. (2008). Marital conflict and support seeking by parents in adolescence: Empirical support for the parentification construct. Journal of Family Psychology, 22(4), 633-642. doi: $10.1037 / \mathrm{a} 0012792$

Pickar, D. B. \& Kaufman, R. L. (2015). Parenting plans for special needs children: Applying a risk- assessment model. Family Court Review, 53(1), 113-133. doi: $10.1111 /$ fcre. 12134

Press, J. \& Fagan, J. (2006). Spousal childcare involvement and perceived support for paid work. Journal of Family and Economic Issues, 27(2), 354-374. doi: $10.1007 / \mathrm{s} 10834-006-9009-8$ 
Priem, J. S., Solomon, D. H., \& Steuber, K. R. (2009). Accuracy and bias in perceptions of emotionally supportive communication in marriage. Personal Relationships, 16(4), 531-552. doi: 10.1111/j.1475-6811.2009.01238.x

Rosa, E. M. \& Tudge, J. (2013). Urie Bronfenbrenner's theory of human development: Its evolution from ecology to bioecology. Journal of Family Theory \& Review, 5(4), 243-258.

Rothausen, T. J. (1994). Job satisfaction and the parent worker: The role of flexibility and rewards. Journal of Vocational Behavior, 44(3), 317-336. doi:

10.1006/jvbe. 1994.1021

Russell-Chapin, L. A., Chapin, T. J., \& Sattler, L. G. (2001). The relationship of conflict resolution styles and certain marital satisfaction factors to marital distress. The Family Journal, 9(3), 259-264.

Smith, A. M. \& Grzywacz, J. G. (2014). Health and well-being in midlife parents of children with special health needs. Families, Systems \& Health: The Journal Of Collaborative Family Healthcare, 32(3), 303-312. doi: 10.1037/fsh0000049

Sobsey, D. (2004). Marital stability and marital satisfaction in families of children with disabilities; Chicken or egg? Developmental Disabilities Bulletin, 32(1), 62-83.

Starr, P. (1981). Marital status and raising a handicapped child: Does one affect the other? Social Work, 26(6), 504-506.

Thurston, S., Paul, L., Loney, P., Ye, C., Wong, M., \& Browne, G. (2011). Associations and costs of parental symptoms of psychiatric distress in a multi-diagnosis group of children with special needs. Journal Of Intellectual Disability Research: JIDR, 55(3), 263-280. doi: 10.1111/j.1365-2788.2010.01356.x 
Vandello, J. A., Hettinger, V. E., Bosson, J. K., \& Siddiqi, J. (2013). When equal isn't really equal: The masculine dilemma of seeking work flexibility. Journal of Social Issues, 69(2), 303-321. doi: 10.1111/josi.12016

Wayne, D. O. \& Krishnagiri, S. (2005). Parents' leisure: The impact of raising a child with Down syndrome. Occupational Therapy International 12(3), 180-194. doi: 10.1002/oti.4

Weaver, J. M. \& Schofield, T. J. (2015). Mediation and moderation of divorce effects on children's behavior problems. Journal of Family Psychology, 29(1), 39-48. doi: $10.1037 /$ fam0000043

Wieland, N. \& Baker, B. L. (2010). The role of marital quality and spousal support in behaviour problems of children with and without intellectual disability. Journal of Intellectual Disability Research, 54(7), 620-633. doi: 10.1111/j.13652788.2010.01293.x

Williams, J. (2010). The odd disconnect: Our family-hostile public policy. In K. Christensen \& B. Scheider (Eds.), Workplace Flexibility: Realigning TweniethCentury Jobs to a Twenty-First-Century Workforce (pp. 107-219). Ithaca, New York: Cornell University Press.

Woody, R. H. (2009). Review of divorce: Causes and consequences. American Journal of Family Therapy, 37(5), 444-446. doi: 10.1080/01926180902945988

Wymbs, B. T., Pelham, W. E., Jr., Molina, B. S. G., Gnagy, E. M., Wilson, T. K., \& Greenhouse, J. B. (2008). Rate and predictors of divorce among parents of youths with ADHD. Journal Of Consulting And Clinical Psychology, 76(5), 735-744. doi: $10.1037 / \mathrm{a} 0012719$ 
Yucel, D. (2017). Work-family balance and marital satisfaction: The mediating effects of mental and physical health. Society and Mental Health, $X X(\mathrm{X}), 1-21$. doi: $10.1177 / 2156869317713069$ 